\title{
Towards the Identification of Type III Effectors Associated with Ralstonia solanacearum Virulence on Tomato and Eggplant
}

\author{
Flora Pensec, Aurore Lebeau, M. C. Daunay, Frédéric Chiroleu, Alice Guidot, and Emmanuel Wicker
}

\begin{abstract}
First, second, fourth, and sixth authors: CIRAD, UMR 53 Peuplements Végétaux et Bioagresseurs en Milieu Tropical (PVBMT), Saint-Pierre, La Réunion, France; third author: INRA, Centre d'Avignon, Unité de Génétique et Amélioration des Fruits et Légumes, UR1052, Montfavet, France; and fifth author: INRA, UMR 441 Laboratoire des Interactions Plantes-Microorganismes (LIPM), Castanet-Tolosan, France. Current address of first author: Institut National de la Recherche Agronomique, UMR A 1131 Santé de la Vigne et Qualité du Vin (SVQV), Colmar, France. Université de Strasbourg, Strasbourg, France.
\end{abstract}

Accepted for publication 7 September 2015.

\begin{abstract}
Pensec, F., Lebeau, A., Daunay, M. C., Chiroleu, F., Guidot, A., and Wicker, E. 2015. Towards the identification of type III effectors associated with Ralstonia solanacearum virulence on tomato and eggplant. Phytopathology 105:1529-1544.

For the development of pathogen-informed breeding strategies, identifying the microbial genes involved in interactions with the plant is a critical step. To identify type III effector (T3E) repertoires associated with virulence of the bacterial wilt pathogen Ralstonia solanacearum on Solanaceous crops, we used an original association genetics approach combining DNA microarray data and pathogenicity data on resistant eggplant, pepper, and tomato accessions. From this first screen, 25 T3Es were further full-length polymerase chain reaction-amplified within a

35-strain field collection, to assess their distribution and allelic diversity. Six T3E repertoire groups were identified, within which 11 representative strains were chosen to challenge the bacterial wilt-resistant eggplants 'Dingras multiple Purple' and 'AG91-25', and tomato Hawaii7996. The virulence or avirulence phenotypes could not be explained by specific T3E repertoires, but rather by individual T3E genes. We identified seven highly avirulence-associated genes, among which ripP2, primarily referenced as conferring avirulence to Arabidopsis thaliana. Interestingly, no T3E was associated with avirulence to both eggplants. Highly virulence-associated genes were also identified: ripA5_2, ripU, and ripV2. This study should be regarded as a first step toward investigating both avirulence and virulence function of the highlighted genes, but also their evolutionary dynamics in natural $R$. solanacearum populations.
\end{abstract}

Effective and durable control of plant pathogens is a critical challenge for global food security. Once a pathogen has established in an area, the use of genetically resistant plants is one of the most effective control approaches, particularly against bacterial pathogens for which chemical control and agricultural practices remain ineffective or unpractical solutions (Strange and Scott 2005). Now the central challenge of this approach is the identification of broadspectrum and durable resistance genes/quantitative trait loci (QTL). Resistance durability was first measured retrospectively (see for example van den Bosch and Gilligan 2003), but recent studies demonstrated that this trait may be inferred from the resistance level and spectrum of the plant R genes/QTL and their genetic background (Palloix et al. 2009; Quenouille et al. 2014). Evolutionary potential of the pathogen (McDonald and Linde 2002), and specifically evolutionary forces at work on the pathogen genes involved in virulence are also important traits for resistance durability. The seminal paper of Leach et al. (2001) proposed that durability of plant $\mathrm{R}$ genes could be inferred from the pathogen fitness penalty induced by adaptation to this gene, including the loss of the cognate avirulence gene (Leach et al. 2001).

In the model currently describing the evolution of plant-pathogen microbes interactions (Jones and Dangl 2006), pathogens secrete effectors that suppress or subvert the resistance responses triggered by microbe-associated molecular patterns (MAMPs). This dichotomy between MAMP-triggered immunity (MTI) and effector-

Corresponding author: E. Wicker; E-mail address: wicker@cirad.fr

*The $\boldsymbol{e}$-Xtra logo stands for "electronic extra" and indicates that one supplementary figure and eight supplementary tables are published online.

http://dx.doi.org/10.1094/PHYTO-06-15-0140-R

(C) 2015 The American Phytopathological Society triggered immunity (ETI) has been recently questioned by Cook et al. (2015), who proposed to consider the plant innate immunity as "a system that evolves to detect invasion." Plant-pathogenic bacteria possess a large repertoire of secreted effectors, where the type III secretion system (T3SS) plays a central role in virulence (Kenny and Valdivia 2009). Numerous functional genetic assays have tried to decipher the respective role of many individual effectors (for a review, see for example Chang et al. 2014; Feng and Zhou 2012), but the association of individual effectors to an avirulence or virulence phenotype remains problematic due to functional redundancy (Cunnac et al. 2011). Genome-wide association mapping may be a promising alternative approach, allowing to associate not only individual genes but gene repertoires to a phenotype (Falush and Bowden 2006). We applied such an approach on the soilborne Beta-Proteobacterium Ralstonia solanacearum, a vascular plant pathogen whose host range is particularly huge (more than 54 botanical families). It induces bacterial wilt on the family Solanaceae but also more than 50 other families (among which include Zingiberaceae, Fabaceae, Myrtaceae, ...), causing heavy losses throughout the tropical and subtropical belt in Asia, Africa, and America. Breeding efforts for resistance to this disease have been hindered for years by the lack of complete resistance genitors, the strong interactions between resistance and local strains, as well as by the huge genomic and phenotypic plasticity of the pathogen. Among proteobacterial plant pathogens, $R$. solanacearum possesses a very large repertoire of genes contributing to virulence, including genes involved in aeroand chimio-tactism (Yao and Allen 2006, 2007), reactive oxygen species (ROS) detoxification (Flores-Cruz and Allen 2011), multidrug efflux pumps (Brown et al. 2007), and Tat secretome (Gonzalez et al. 2007), but the secreted proteins (effectors) distributed by the T3SS constitute the key virulence factors (Poueymiro 
and Genin 2009). Whereas most proteobacterial plant pathogens possess 20 to 30 type III effectors (T3E), $R$. solanacearum metarepertoire gathers 94 families (orthologous groups) (Peeters et al. 2013), and individual strains usually carry 60 to 75 effectors (Deslandes and Genin 2014). Genes governing specific plant- $R$. solanacearum interactions have been identified in the model plants Arabidopsis thaliana and Medicago truncatula (for a review, see Deslandes and Genin [2014]). The most documented example is the acetyltransferase popP2 (Deslandes et al. 2003), recently renamed ripP2 (Peeters et al. 2013), whose interaction with the $A$. thaliana gene $R R S 1-R$ (Deslandes et al. 1998, 2002) and the cysteine protease RD19 (Bernoux et al. 2008) triggers plant immunity, making it the first avirulence gene described in $R$. solanacearum. It was recently demonstrated that RRS1-R forms a receptor complex with RPS4 (conferring resistance to Pseudomonas syringae) that detect the WRKY-targeting effectors, and convert the lysine-acetylase activity of RipP2 to immunity (Le Roux et al. 2015; Sarris et al. 2015). Other effectors have been identified, such as the cysteine protease ripP1 that elicits a hypersensitive response (HR) on some Petunia (Poueymiro et al. 2009; Poueymiro and Genin 2009) and tobacco species, and RipG7 which is required for pathogenicity on Medicago truncatula (Angot et al. 2006). Whereas, bacterial genetic factors that are critical for virulence and avirulence to cultivated species remain largely unknown. The zinc-dependent protease rip36 (Nahar et al. 2014), renamed ripAX2 (Peeters et al. 2013), induces a HR on Solanum torvum, a wild relative of eggplant. RipA2 contributes to pathogenicity to tomato, whereas ripA5 elicits a HR-like on some tobacco species (Sole et al. 2012). The ripG2, ripG3, ripG6, and ripG7 effector proteins collectively contribute to pathogenicity to tomato and Arabidopsis (Remigi et al. 2011).

By challenging reference resistance genitors of tomato, eggplant, and pepper (Core-TEP) to a worldwide collection of $R$. solanacearum strains (core-RS2), Lebeau et al. (2011) identified several cases of "incompatible interactions," phenotyped as "no wilt and no colonization," that may be indicative of gene-for-gene interactions. One of the accessions involved in such incompatible interactions was eggplant AG91-25, which carries the ERs1 resistance gene (Lebeau et al. 2013). The core-RS2 strains were hybridized on a DNA microarray (Guidot et al. 2009; Remenant et al. 2010) in order to get access to their gene content. The combined analysis of such genotypic and phenotypic data was carried out in order to identify phenotype-associated genes.

In this study, we thus aimed to identify, by a top-down approach sensu Falush and Bowden (2006), the R. solanacearum T3E gene repertoires associated with avirulence or virulence phenotypes on resistant eggplant, pepper, and tomato cultivars. The specific questions we addressed were as follows. (i) What is the T3E distribution variability in a large strain collection? (ii) Is the virulence on Solanaceae explained by T3E repertoires, individual $\mathrm{T} 3 \mathrm{E}$ presence/absence, or individual T3E allelic differences? (iii) Are the avirulence/virulence effectors involved in interactions with several cultivars, or is there cultivar specificity (Lewis et al. 2014)?

\section{MATERIALS AND METHODS}

Bacterial strains. Two $R$. solanacearum strain collections were used for this study. A first set of 12 international strains called core-RS2 was selected from a global reference collection, based on their aggressiveness on tomato, eggplant, and pepper susceptible reference accessions (Lebeau et al. 2011); this was used from the first step of this study. Two additional strains belonging to the highly harmful "emerging ecotype" (Wicker et al. 2007) were added to this set but were studied only from the second step of our study. The second set gathered 35 environmental strains collected on different diseased hosts throughout Reunion Island (Table 1). Bacterial strains were all stored in Cryobank beads at $-80^{\circ} \mathrm{C}$. They were grown first on nutrient broth overnight at $28^{\circ} \mathrm{C}$, and then streaked $(50 \mu \mathrm{l})$ on Kelman's triphenyl tetrazolium chloride (TZC) agar medium (Kelman 1954) supplemented with $1 \%$ yeast extract and subcultured 2 days at $28^{\circ} \mathrm{C}$. Bacterial DNA was extracted from fresh cultures $\left(\sim 1.0\right.$ to $2.0 \times 10^{9}$ cells), using the DNeasy Blood and Tissue kit (QIAGEN) following the manufacturer's instructions for gram-negative bacteria. DNA solutions were then quantified with a NanoDrop ND-8000 spectrophotometer (NanoDrop Technologies Inc., Wilmington, DE), adjusted to $10 \mathrm{ng} \mathrm{ll}^{-1}$, and stored at $-20^{\circ} \mathrm{C}$ until use.

Plant accessions. Tomato, eggplant, and pepper accessions were chosen within the core-TEP according to their bacterial wiltresistance level and spectrum (Lebeau et al. 2011) (Table 2). For tomato, L390 (coded T10 throughout the article) is highly susceptible (Lebeau et al. 2011; Truong et al. 2008; Wang et al. 1998). The accession Hawaii7996 (encoded T5) displays the highest resistance level, and controls the broadest spectrum of strains (Lebeau et al. 2011); it is also the best known bacterial wiltresistant tomato accession, with several mapped QTLs (Carmeille et al. 2006; Wang et al. 2013; Wang et al. 2000). For eggplant, the susceptible accession chosen was MM738 (encoded E8 by Lebeau et al. [2011] and in the following), given its high susceptibility (Lebeau et al. 2011) and its status of susceptible parent of the mapping population MM738 × AG91-25 (Lebeau et al. 2013). The resistant accessions chosen display complete incompatible interactions (i.e., no wilt and no stem colonization) with at least one $R$. solanacearum strain of the core-RS2: (i) Dingras multiple Purple, referenced as MM853 in INRA germplasm collection (E1 in this study), displays both a high resistance level and a broad resistance spectrum; (ii) SM6, referenced as MM643 (E2 in this study), is completely resistant to phylotype IIB "emerging strains" (Deberdt et al. 2014; Lebeau et al. 2011) but also IIA and III strains (detailed in Table 3); (iii) Ceylan, referenced as MM152 (E3 in this study), is completely resistant to phylotype I, IIA, and III strains (Table 3); (iv) Surya, referenced as MM1811 (E4 in this study), is resistant to IIA and III strains; and (v) AG91-25, referenced as MM960 (E6 in this study), is totally resistant to strain CFBP6942 (encoded RUN0145) and is poorly colonized by CFBP7032 (RUN0150) and PSS366 (RUN0155), whereas susceptible to virulent strains (N'Guessan et al. 2012). AG91-25 also carries the dominant gene Ers1, the first bacterial wilt-resistance gene identified in a crop (Lebeau et al. 2013). For pepper, resistant accessions were (i) P687 (P2 in this study), resistant to phylotype I strains; (ii) CA8, referenced as PM1580 (P6 in this study), resistant to phylotype IIA strains; and (iii) Perennial, referenced as PM659 (P8 in this study), resistant to phylotype III strains (Table 3).

Comparative genomic hybridization (CGH) data. The DNA microarray used in these experiments, generated by C. Boucher and collaborators (INRA-CNRS, Toulouse, France), consisted of 6,516 65-mer and 70-mer oligonucleotides representative of the genes identified within the $R$. solanacearum genomes GMI1000 (phylotype I), IPO1609 (phylotype IIB/clade 5/sequevar 1), and MOLK2 (phylotype IIB/clade 5/sequevar 3), as previously described (Remenant et al. 2010; Wicker et al. 2012). Each gene was represented by a single oligonucleotide, except for 117 T3E or effector-like genes, which were represented by two to six oligonucleotides to distinguish allelic forms of a given gene. Each oligonucleotide was spotted twice on a microarray. DNA extraction and labeling, microarray hybridization, hybridization analyses, and gene detection threshold are detailed in Guidot et al. (2007) and Remenant et al. (2010). Effector data sets were complete for 10 core-RS2 strains; however in the case of PSS4 (RUN0157) and PSS366 (RUN0155), only 65 effectors out of 117 were correctly identified. In downstream analyses, these two strains were thus analyzed apart from the others.

Identification of genes associated with effector probes. The correspondence between original probe names and Rip T3E new nomenclature (Peeters et al. 2013) was established by using the RalstoT3E website hosted by the Laboratory of Plant Microbe Interactions (LIPM), Toulouse (https://iant.toulouse. inra.fr/bacteria/annotation/site/prj/T3Ev2/). 
Genotype/phenotype association workflow. The whole process, articulated in three main steps, is summarized in Figure 1.

Step 1: CGH screening of gene repertoires for association with virulence. In the literature, genes that were experimentally demonstrated as involved in $R$. solanacearum virulence are genes encoding type III effectors (T3E) and the T3SS (Poueymiro and Genin 2009), genes involved in bacterial motility (Tans-Kersten et al. 2001, 2004), aero-and chemotaxis (Yao and Allen 2006, 2007), transcription regulation, toxin resistance (Brown et al. 2007; Gonzalez et al. 2007), and genes encoding extracellular enzymes secreted through the type II secretion system (Denny 2006). In this work, we focused on the distribution of type III effectors or T3E-like coding sequences within the 12 strains of the first collection, and on their association with virulence phenotypes. Distribution patterns of the other genes were investigated in a preliminary study but no correlation with virulence phenotypes was found.

We considered 117 genes present on the $7 \mathrm{~K}$ microarray, including 79 T3E sensu Poueymiro and Genin (2009) and 10 putative T3Es, six genes ( $h p a B, h r p Z, h r p Y, h r p X, h r p W$, and $h r p V$ ) coding for the T3SS, and 22 coding sequences that shared homologous domains with T3E from different bacterial genera, or that contained homeobox domain. Each gene or coding sequence was represented by two to five probes.

Association of type III effectors with virulence or avirulence on Solanaceae. To identify genes associated with virulence or avirulence, we considered published phenotyping data obtained on the core collections of bacterial wilt-resistant tomato, eggplant, and pepper (core-TEP) (Lebeau 2010; Lebeau et al. 2011). We particularly focused on plant accessions displaying incompatible interactions (defined on this pathosystem as "zero wilting and zero colonization") with at least one $R$. solanacearum strain, i.e., (i) eggplant lines Dingras Multiple Purple (MM853), SM6 (MM643), Ceylan (MM152), Surya (MM1811), and AG91-25 (MM960), respectively encoded here as E1, E2, E3, E4, and E6; (ii) pepper lines PM687, CA8 (PM1580), and Perennial (PM659), respectively encoded P2, P6, and P8; and (iii) tomato Hawaii7996 (encoded T5) (Lebeau et al. 2011) (Table 3). Thus, we distinguished an avirulent

TABLE 1. Characteristics of Ralstonia solanacearum strains belonging to the world collection core-RS2 and to the Reunion Island collection

\begin{tabular}{|c|c|c|c|c|c|}
\hline Strain & RUN number & Host & Origin & Phylotype & Sequevar \\
\hline \multicolumn{6}{|c|}{ Core-RS2 (Lebeau et al. 2011) } \\
\hline GMI1000 & 54 & Solanum lycopersicum & French Guiana & I & 18 \\
\hline PSS366 & 155 & Solanum lycopersicum & Taiwan & I & 15 \\
\hline PSS004 & 157 & Solanum lycopersicum & Taiwan & I & 15 \\
\hline PSS358 & 159 & Solanum lycopersicum & Taiwan & I & 15 \\
\hline CFBP7058 & 215 & Solanum scabrum & Cameroon & I & 13 \\
\hline CFBP2957 & 36 & Solanum lycopersicum & Martinique & IIA & 36 \\
\hline CFBP7032 & 150 & Solanum lycopersicum & Cameroon & IIA & 41 \\
\hline CFBP6783 & 17 & Heliconia rostrata & Martinique & IIB & $4 \mathrm{NPB}$ \\
\hline CFBP7029 & 147 & Solanum lycopersicum & Cameroon & IIB & 1 \\
\hline CFBP3059 & 39 & Solanum melongena & Burkina Faso & III & 23 \\
\hline CFBP6941 & 133 & Solanum lycopersicum & Cameroon & III & 29 \\
\hline CFBP6942 & 145 & Solanum scabrum & Cameroon & III & 29 \\
\hline \multicolumn{6}{|c|}{ Emerging ecotype strains } \\
\hline CFBP6784 & 16 & Anthurium andreanum & Martinique & IIB & $4 \mathrm{NPB}$ \\
\hline ANT80 & 18 & Anthurium andreanum & Martinique & IIB & $4 \mathrm{NPB}$ \\
\hline \multicolumn{6}{|c|}{ Collection from Reunion Island } \\
\hline JT519 & 471 & Pelargonium & - & I & 31 \\
\hline JT523 & 608 & Solanum tuberosum & - & I & 31 \\
\hline JQ1044 & 930 & Pelargonium & Trois Bassins & I & NA \\
\hline JQ1143 & 58 & Solanum tuberosum & Bois Court & IIA & 39 \\
\hline JT510 & 59 & Solanum tuberosum & Notre Dame de la Paix & IIB & 1 \\
\hline JT516 & 160 & Solanum tuberosum & - & IIB & 1 \\
\hline JS529 & 476 & Solanum tuberosum & - & IIB & 1 \\
\hline CFBP4801 & 623 & Solanum lycopersicum & - & IIB & 1 \\
\hline LNPV28.23 & 654 & Solanum tuberosum & - & IIB & 1 \\
\hline JT511 & 681 & Solanum tuberosum & - & IIB & 1 \\
\hline JT514 & 697 & Solanum tuberosum & - & IIB & 1 \\
\hline JQ1006 & 843 & Solanum tuberosum & Notre Dame de la Paix & IIB & 1 \\
\hline JQ1073 & 845 & Solanum lycopersicum & Saint Pierre & IIB & 1 \\
\hline JQ1023 & 848 & Solanum lycopersicum & Mont Vert & IIB & 1 \\
\hline JQ1078 & 880 & Solanum lycopersicum & Saint Pierre & IIB & 1 \\
\hline JQ1107 & 889 & Solanum tuberosum & Bois Court & IIB & 1 \\
\hline JQ1006 & 919 & Solanum tuberosum & Notre Dame de la Paix & IIB & 1 \\
\hline JQ1007 & 921 & Solanum tuberosum & Grand Tampon & IIB & 1 \\
\hline JQ1009 & 923 & Solanum tuberosum & Piton Maho & IIB & 1 \\
\hline JQ1017 & 924 & Solanum tuberosum & Plaine des Cafres & IIB & 1 \\
\hline JQ1018 & 925 & Solanum tuberosum & Piton Hyacinthe & IIB & 1 \\
\hline JQ1019 & 926 & Solanum tuberosum & Notre Dame de la Paix & IIB & 1 \\
\hline JQ1023 & 928 & Solanum lycopersicum & Mont Vert & IIB & 1 \\
\hline JQ1051 & 931 & Solanum lycopersicum & Grand Anse & IIB & 1 \\
\hline JQ1078 & 934 & Solanum lycopersicum & Saint Pierre & IIB & 1 \\
\hline JQ1101 & 936 & Solanum lycopersicum & Grand Tampon & IIB & 1 \\
\hline JQ1131 & 941 & Solanum tuberosum & Piton Hyacinthe & IIB & 1 \\
\hline CFBP2148 & 944 & Solanum tuberosum & - & IIB & 1 \\
\hline JT525 & 60 & Pelargonium & - & III & 19 \\
\hline JT528 & 61 & Solanum tuberosum & - & III & 19 \\
\hline NCPPB 1029 & 77 & Pelargonium & - & III & 19 \\
\hline CFBP4963 & 523 & Solanum tuberosum & - & III & 19 \\
\hline CFBP2146 & 657 & Pelargonium & - & III & 19 \\
\hline CFBP4964 & 693 & Pelargonium & Trois Bassins & III & 19 \\
\hline JQ1092 & 913 & Solanum tuberosum & Tan Rouge & III & NA \\
\hline
\end{tabular}


strains pool and a virulent strains pool for each accession considered, and compared their gene content as estimated from CGH data. All probes present in avirulent pool and absent in virulent pool were assigned to the putative avirulence gene probes, whereas all probes absent in avirulent pool and present in virulent pool were assigned as putative virulence gene probes. We then assessed the association of each T3E gene with avirulence/virulence by considering the frequency of its respective probes within avirulent strains and virulent strains pools.

Step 2: PCR genotyping on selected type III effector genes. The CGH data screening allowed to retain a set of 25 genes,

TABLE 2. Genetic resources in tomato, eggplant, and pepper, selected in the core-TEP collection (Lebeau et al. 2011)

\begin{tabular}{|c|c|c|c|}
\hline Code & Accession & Species & $\begin{array}{c}\text { Inoculated in } \\
\text { step } 3\end{array}$ \\
\hline \multicolumn{4}{|c|}{ Tomato } \\
\hline T5 & Hawaii7996 & Solanum lycopersicum & Yes \\
\hline $\mathrm{T} 10$ & L390 & $\begin{array}{l}\text { S. lycopersicum var. } \\
\text { cerasiforme }\end{array}$ & Yes \\
\hline \multicolumn{4}{|c|}{ Eggplant } \\
\hline E1 & $\begin{array}{l}\text { Dingras multiple } \\
\text { Purple, MM853 }\end{array}$ & S. melongena & Yes \\
\hline $\mathrm{E} 2$ & SM6, MM643 & S. melongena & No \\
\hline E3 & Ceylan, MM152 & S. melongena & No \\
\hline E4 & Surya, MM1811, EG203 & S. melongena & No \\
\hline E6 & AG91-25, MM960 & S. melongena & Yes \\
\hline E8 & MM738 & S. melongena & Yes \\
\hline \multicolumn{4}{|l|}{ Pepper } \\
\hline $\mathrm{P} 2$ & PM687 & Capsicum аппиит & No \\
\hline P6 & PBC631A, CA8, PM1580 & C. аппиит & No \\
\hline P8 & Perennial, PM659 & C. annuиm & No \\
\hline
\end{tabular}

a $\mathrm{MM}$ and PM numbers correspond to accession codes in the INRA Germplasm Collection.

TABLE 3. Summary of the avirulent/virulent Ralstonia solanacearum strain pools, as defined by their virulence phenotypes on eggplant (E code), tomato ( $\mathrm{T}$ code), and pepper ( $\mathrm{P}$ code) accessions $^{\mathrm{a}}$

\begin{tabular}{|c|c|c|}
\hline Accession (code) & Avirulent (phenotype 0) & Virulent (phenotypes 4 to 5 ) \\
\hline \multicolumn{3}{|l|}{ Eggplant } \\
\hline \multirow[t]{3}{*}{ Dingras (E1) } & CMR32 & CFBP6783 \\
\hline & CFBP2957 $\bigcirc$ & \\
\hline & GMI1000 $\square$ & \\
\hline \multirow[t]{3}{*}{ SM6 (E2) } & CMR32 घ & PSS4 $\square$ \\
\hline & CFBP2957 $\bigcirc$ & PSS366 $\square$ \\
\hline & CFBP6783 & \\
\hline \multirow[t]{5}{*}{ Ceylan (E3) } & CMR32 घ & CFBP6783 \\
\hline & CMR15 घ & \\
\hline & CFBP2957 $\bigcirc$ & \\
\hline & CMR39 $\bigcirc$ & \\
\hline & PSS358 $\square$ & \\
\hline \multirow[t]{2}{*}{ Surya (E4) } & CMR32 = & CMR15 - \\
\hline & CFBP2957 $\bigcirc$ & \\
\hline \multirow[t]{4}{*}{ AG91-25 (E6) } & CMR32 - & CFBP3059 \\
\hline & CMR39 $\bigcirc$ & CMR15 घ \\
\hline & & CFBP6783 \\
\hline & & CMR34 \\
\hline \multicolumn{3}{|l|}{ Tomato } \\
\hline \multirow[t]{3}{*}{ Hawaii7996 (T5) } & CMR32 घ & CMR15 घ \\
\hline & CMR39 $\bigcirc$ & CMR34 \\
\hline & & CFBP6783 \\
\hline \multicolumn{3}{|l|}{ Pepper } \\
\hline \multirow[t]{3}{*}{ PM687 (P2) } & PSS358 $\square$ & CFBP3059 \\
\hline & & CFBP6783 \\
\hline & & CMR39 $\bigcirc$ \\
\hline \multirow[t]{2}{*}{ CA8 (P6) } & CFBP2957 $\bigcirc$ & CFBP6783 \\
\hline & CMR39 $\bigcirc$ & \\
\hline Perennial (P8) & CMR15 = & CFBP6783 \\
\hline
\end{tabular}

a Avirulence was defined as complete absence of wilt and colonization on the plant accession. Virulent strains were able to colonize and wilt accessions, inducing a phenotype 4 or 5 sensu Lebeau et al. (2011). R. solanacearum strains belong to phylotype I $(\square)$, IIA $(\bigcirc)$, IIB (O), or III (ם). associated with virulence or avirulence. The distribution of these 25 genes was PCR-checked within the two strain collections described above. These genes consisted of two harpin genes, popW (Li et al. 2010) and hrpZ (Lin et al. 2010), and 23 putative or validated type III effectors (Peeters et al. 2013).

PCR primer design. Since effector gene sequences are available for only a few strains belonging to our collections, we aligned orthologous effector sequences of GMI1000 (phylotype I), CMR15 (phylotype III), PSI07 (phylotype IV), IPO1609, Molk2 (both in phylotype IIB), and CFBP2957 (phylotype IIA). Orthologous gene families were defined from the T3E sequences found within the complete genome sequences harbored in the Mage Web interface (https://www.genoscope.cns.fr/agc/microscope/home/index.php) of the MicroScope platform. On this platform, search for orthologous genes was performed by applying the following parameters: (i) gene identity above $80 \%$; (ii) ratios of alignment lengths computed for each comparison using the BLAST software (minLrap and maxLrap) above $90 \%$. We also used the RalstoT3E website (https://iant.toulouse. inra.fr/bacteria/annotation/site/prj/T3Ev2/) to assign each coding sequence to an rip family following the nomenclature proposed in the reference paper of Peeters et al. (2013).

Based on these alignments, we identified conserved zones and designed the primers that would enable to amplify putative T3E in all the strains studied. When possible, the primers were designed to amplify entire genes; for gene sizes exceeding $1 \mathrm{~kb}$, primers were designed to amplify several gene fragments. Primer design was performed using the Primer 3 software (http://bioinfo.ut. ee/primer3-0.4.0/primer3/input.htm) following the parameters: annealing temperature around $60^{\circ} \mathrm{C}$ and primer size between 18 and 25 nucleotides.

Gene amplification and visualization. For each strain, putative effectors were PCR amplified on $20 \mathrm{ng}$ of sample DNA template. PCR reactions (total volume of $25 \mu \mathrm{l}$ ) consisted of $1 \mathrm{U}$ of Red Goldstar Taq DNA polymerase, 25 pmol of each primer, $1 \times$ PCR buffer, $1.5 \mathrm{mM} \mathrm{MgCl}_{2}, 0.2 \mathrm{mM}$ of each dNTPs, and 1× Q-solution. The reaction was cycled in Eppendorf Mastercycler Gradient or Applied Biosystems GenAmp PCR System 9700 thermocyclers with a first denaturation step at $96^{\circ} \mathrm{C}$ for $5 \mathrm{~min}$ followed by 30 cycles of $30 \mathrm{~s}$ at $95^{\circ} \mathrm{C}, 60 \mathrm{~s}$ at $56^{\circ} \mathrm{C}$, and $60 \mathrm{~s}$ at $72^{\circ} \mathrm{C}$, and a final elongation step of $10 \mathrm{~min}$ at $72^{\circ} \mathrm{C}$. All PCR products were resolved on a $2 \%$ agarose gel and visualized with UV light after ethidium bromide staining $\left(5 \mu \mathrm{g} \mathrm{ml}^{-1}\right)$; fragment sizes were estimated as compared with a 100-bp DNA ladder (New England BioLabs).

Step 3: Pathogenicity tests (phenotyping) with representative strains. Tomato (susceptible T10, and resistant T5) and eggplant (susceptible E8, resistant E1 and E6) seeds were sown in a greenhouse for 4 and 3 weeks, respectively, before inoculation and were transplanted 1 week later into FLORADUR potting mix $(9 \times$ $9 \mathrm{~cm}$ pots). Once three to four fully expanded leaves was reached, plants were transferred (at least 2 days before inoculation) into a high quarantine security level (NS3) growth chamber (Rotoplan), to cope with inoculation of exotic strains (notably from the "emerging ecotype" [phylotype IIB/clade 4/sequevar 4NPB]). Climatic parameters were set at $85 \%$ relative humidity, with a photoperiod of $12 \mathrm{~h}$, and a thermoperiod of $30^{\circ} \mathrm{C}$ day $/ 24^{\circ} \mathrm{C}$ night $\left( \pm 2{ }^{\circ} \mathrm{C}\right)$. Bacterial suspensions of selected strains were prepared in Tris buffer $\left(10^{8}\right.$ cells $\left.\mathrm{ml}^{-1}\right)$ and inoculated $(5 \mathrm{ml}$ per plant $)$ as previously described (N'Guessan et al. 2012) after root scarification. Each strain was inoculated on 15 plants from each accession. The experiment was repeated once. Bacterial wilt incidence and severity were monitored every 2 to 3 days for 28 days on a 0 to 4 scale that conveys the percentage of leaves wilted (N'Guessan et al. 2012). Each plant that scored 3 and 4 was considered wilted. Plants showing no symptoms at the end of the experiment were harvested and sampled for latent infections as previously described (Deberdt et al. 2014; Lebeau et al. 2011; N'Guessan et al. 2012). The percentage of wilted plants and the colonization index (Prior et al. 1996) were thus accessed. 
Data analysis. All statistical analyses were done using R software version 3.1.3 (R Development Core Team 2013).

Typologies of T3E gene repertoires (step 2). For each strain, the expected PCR results were (i) presence or absence of the T3E, as estimated by PCR amplification success or failure, and (ii) the size of the amplified fragment. For each putative gene, class 1 corresponded to a fragment amplification of the expected size, class 2 referred to no amplification, and classes 3 to 6 corresponded to the different alleles (band size) obtained after amplification. Each class, named "allele score" further down in the paper, was considered a qualitative factor within each variable (T3E gene or coding sequence [CDS]). The strains were then clustered on the basis of each allele score for all 25 genes amplified, using an agglomerative hierarchical clustering (Maechler et al. 2015) with the Euclidean distance and considering the "Ward" method. We identified the variables (genes) best describing each cluster (named type III effector repertoire group [TRG] further down) by using a $\chi^{2}$ test (Husson et al. 2009, 2015).

Comparison of wilting and colonization rates across strains (step 3). The effect of strain and plant accession on wilting and colonization incidence, and area under the disease progression curve (AUDPC), was assessed using a generalized linear model considering, respectively, binomial data (wilted versus nonwilted) with $\chi^{2}$ test $(P=0.05)$, and an analysis of variance with FisherSnedecor test $(P=0.05)$. Incidence and AUDPC means were compared within each plant accession using a pairwise comparison test based on the Tukey's methods at 0.05 (Hothorn et al. 2008).

Typologies of virulence phenotypes (step 3). The combination of final wilting incidence and colonization index scores was used

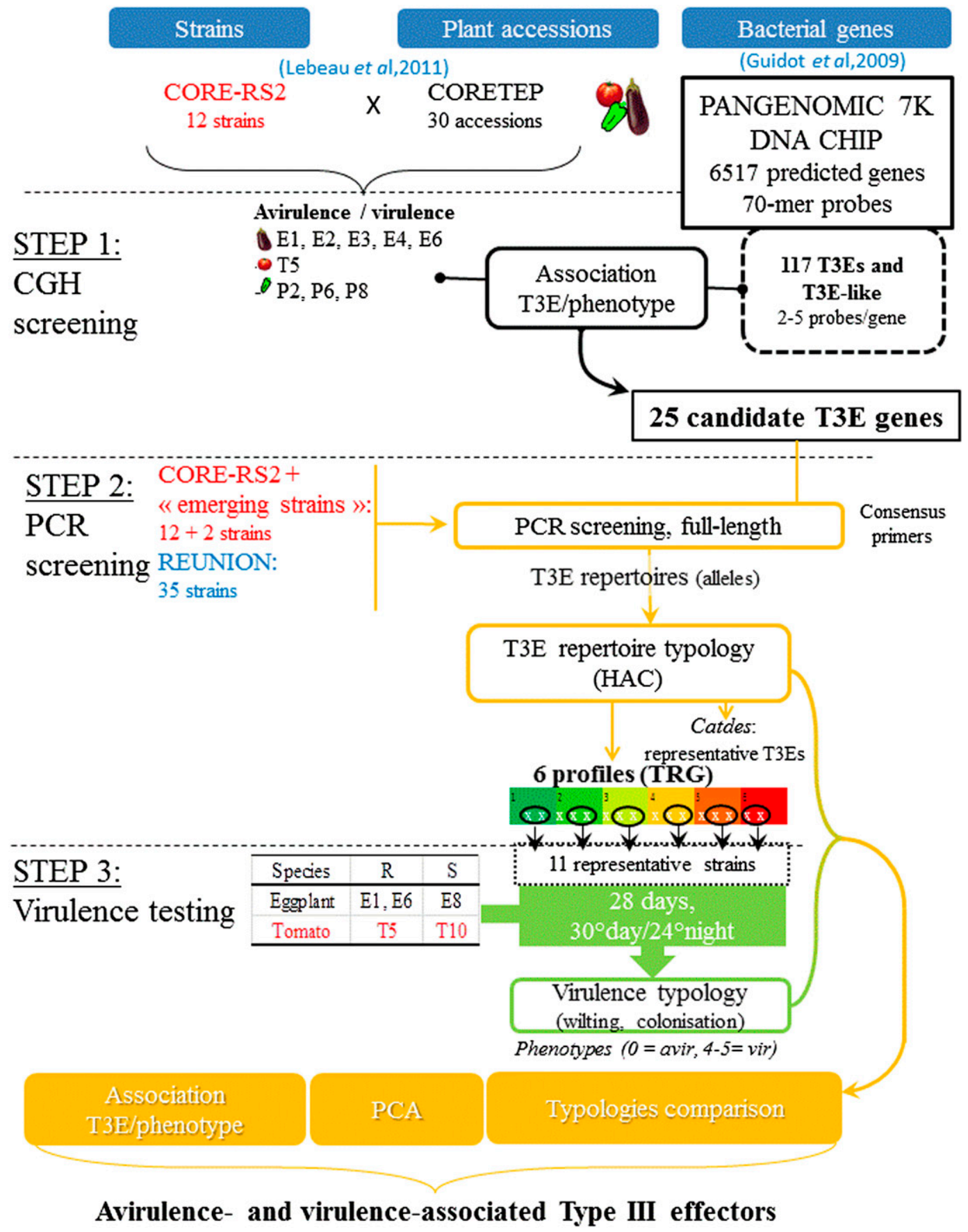

Fig. 1. Genotype-phenotype association workflow. Data priming this study were generated by Lebeau (2010), Lebeau et al. (2011), and Guidot et al. (2009). T3E: type III effector; HAC: hierarchical ascending classification; and TRG: type III effector repertoire group. In step 3, the eggplant accessions were either resistant (R) or susceptible (S). 
to calculate reference phenotypes using the " $k$-nearest neighbor" algorithm (Venables and Ripley 2002) as previously described (Lebeau et al. 2011; N'Guessan et al. 2012). Virulence phenotypes ranged from 1 (highly resistant) to 5 (highly susceptible). The 0 class used in this study corresponded to no wilt and no colonization. Each representative strain was thus assigned to a virulence phenotype on the different plant accessions. The virulence phenotypes were considered as ordered factors ranked in ascending order from 0 to 5 . A phenotype clustering was constructed by using an agglomerative hierarchical clustering as described above, considering each accession separately.

A principal component analysis based on gene presence/absence patterns and the phenotype on the different resistant accessions (E1, E6, and T5) was performed using the ade4 package (Dray and Dufour 2007).

\section{RESULTS}

T3E distribution within the core-RS2 as estimated by CGH. We first aimed to assess the distribution of 117 genes coding for proteins secreted by, or constitutive of the structure of, the type III secretion system, within the reference 12-strain core-RS2 collection. Among the 117 genes considered, 91 were T3E (78) or putative T3E (13) (Supplementary Table S1). Considering the 10 strains with complete validated hybridization results (i.e., apart from PSS366 [RUN0155] and PSS04 [RUN0157]), the distribution of the $91 \mathrm{~T} 3 \mathrm{E}$ genes was compared across the core-RS2 strains. It is important to note that we considered the gene present in a strain if this strain was positive for at least one probe of this gene. We also compared this CGH-based repertoire to the repertoire of 26 genomes available on the RalstoT3E website. Twenty T3E genes, sensu Peeters et al. (2013), were absent or were not detected in our conditions, from this core-RS2 collection: $\operatorname{rip} A F 2$, ripAG, ripAI (RSp0838), ripAZ2, ripBA_fragment2 ( $\mathrm{RSc} 0228)$, ripBB, ripBC, ripBD, ripBF, ripBG, ripC2_Fragment 1 and 2 (RSp0593 and 0592, respectively), $\operatorname{rip} F 2, \operatorname{rip} G 8, \operatorname{ripH} 4, \operatorname{ripK}, \operatorname{ripO} 2, \operatorname{ripP} 3$ fragment 1 and 2 (RSc3444 and 3443, respectively), ripS6, ripS7, and ripS8 (RSc3447). Except ripAI which was found to be a core-effector (Ailloud et al. 2015; Clarke et al. 2015; Peeters et al. 2013), most of these "lacking effectors" were either phylotype IV-specific (as detailed below) or found within phylotype IIB strains.

Type III effector repertoires ranged from 61 (CMR32) to 79 (GMI1000). Although there was no clear relationship between phylotype and repertoire richness, phylotype III strains seemed to contain fewer T3Es (61 to 67) than the other phylotypes: 74 to 78 in phylotype I, 73 to 77 in phylotype IIA, and 74 to 75 in phylotype IIB (Supplementary Table S2). Forty-one T3E genes and three putative T3Es were common to all 10 strains, among which four ripA (ripA2-5), four ripG (ripG2-5), three ripH (ripH1-3), and four ripS (ripS1-4). Conversely, ripA5_2 was the least shared T3E (20\% strains), as well as ripT and ripG1 (30\% strains). To check for the effector prevalence evenness within our collection, and detect eventual phylotype-specific effectors, we compared the distribution of the 91 T3E genes within each phylogenetic group (phylotype I, three strains; phylotype II, four strains; and phylotype III, three strains). Effector distributions within phylotypes were not significantly different from expected ( $\chi^{2}$ test, $P$ value $=0.999$ to 1 ), indicating that phylotype had no detectable influence on effector distribution. Considering the distribution of individual T3E across phylotypes, only ripA5_2 (PTO1391) and ripCl had a distribution different from expected ( $\chi^{2}$ test, $P$ value $=0.038$ for both), the first one appearing specific to phylotype II while the latter was found absent from phylotype III strains.

Considering the 12 strains (including PSS366 and PSS4), only 65 T3Es gave unambiguous scorable results. From the comparison of T3E distribution across phylotypes (phylotype I containing five strains this time), the conclusions were highly similar (no apparent phylotype-specific T3E composition), except that (i) ripGl looked significantly overrepresented in phylotype I, and (ii) ripBH was overrepresented in phylotype II ( $\chi^{2}$ test, $P$ value $=0.044$ and 0.020 , respectively).

The effector prevalence evenness was also assessed on the 26 $R$. solanacearum genomes harbored on the RalstoT3E website (Supplementary Table S3). It is important to note that this data set included phylotype I genomes (four, including GMI1000), numerous phylotype II genomes (four IIA including CFBP2957, and 14 IIB including CFBP6783), phylotype IV genomes (three), but contained one single phylotype III genome (CMR15). Type III effector repertoires ranged from 68 to 75 for phylotype I, from 54 to 67 for phylotype IIA, from 54 to 70 for phylotype IIB, 59 for phylotype III, and from 46 to 62 for phylotype IV. Effector distributions within phylotypes were significantly different from expected for phylotype IV and phylotype I $\left(\chi^{2}\right.$ test, $P$ value $=0.014$ and 0.029 , respectively). Considering the distribution of individual T3E across phylotypes, 15 effectors had a distribution different from expected. Most of them were significantly specific to phylo-

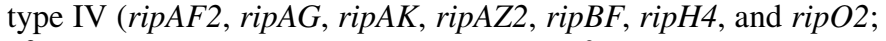
$\chi^{2}$ test, $P$ values ranging between $5.88 \times 10^{-6}$ and 0.029 ), or to both phylotypes IV and I (ripT, $P=0.004$ ), or specific to phylotype I (ripA1, ripAH, ripBA, ripS6, ripS8, and ripTAL; $P$ values ranging from $3.25 \times 10^{-4}$ to 0.025$)$. RipG8 was specific to phylotype III $\left(P=1.831 \times 10^{-6}\right)$. We confirmed that $\operatorname{rip} G 1$ was significantly overrepresented within phylotype I, whereas absent within phylotype II genomes $(P=0.004)$; ripBH was found in both phylotype II and phylotype IV genomes, and its distribution was thus not different from expected $(P=0.171)$.

Analysis of effector repertoires of the core-RS2 reveals the association of some T3Es to specific virulence phenotypes. Comparing the presence of each probe within each couple of avirulent and virulent strain panels (Table 3 ), we chose to rely on the ratio "present probes/total probes per gene" to infer a degree of association to a particular phenotype. As an example, ripPl was $100 \%$ associated with avirulence to eggplant 'Surya' (Table 4) because all three ripPl probes were present in all avirulent strains, whereas absent in all virulent strains.

Association with avirulence. Sixty genes were associated with avirulence, mainly to pepper P8 (35 genes), then eggplant E6 (28 genes), E2 (11 genes), E1 (10 genes), E3 (four genes), and E4 (two genes). One single gene, ripAX2, was associated with avirulence to tomato T5 (Table 4). Interestingly, 20 genes were associated with avirulence to two accessions (mostly one eggplant and pepper P8), and five genes were associated with avirulence to three cultivars: ripA4 and ripN on E1-E6-P8; ripAS on E3-E6-P8; ripD on E2-E6P8; and ripG5 on E1-P6-P8 (Supplementary Table S4).

We focused on the 31 genes (one harpin, four putative T3Es, 26 T3Es among which ripAP was in two fragments) (i) whose at least $50 \%$ probes (corresponding to 0.5 in Table 4 ) were associated with avirulence to at least one accession, and/or (ii) were associated with avirulence to E1 or E6 even with less than $50 \%$ probes (Table 4 ), and/or (iii) were related to fitness on one or several hosts in a previous study (Macho et al. 2010). Highest association scores (from 1 down to 0.67) were observed with avirulence to E6 (ripAP-ripE1, ripP2, ripAJ-ripAU-ripAZ1ripP1), P8 (RSp0216, RSp0218-ripAS, ripG3), E4 (ripP1, ripAZ1), and T5 (ripAX2). Some effectors were associated with avirulence to more than one accession. Indeed, avirulence to both E1 and P8 was associated with four effectors ( $h r p Z$, ripG4, ripS5, and RSc1723); avirulence to E3 and P8 with two (Rsp0216 and RSp0218), like E4 and E6 (ripAZ1 and ripP1); and avirulence to E6 and P8 was associated with ripG3 (Table 4). Three genes were even associated with avirulence on three accessions: ripAS (E3-E6-P8), ripN (E1-E6-P8), and ripG5 (E1-P6-P8). Effectors associated with avirulence to E1 were unexpectedly few and mildly associated (one probe/gene): hrpZ, ripG4, ripG5, ripN, ripS5, and RSc1723. Only ripN was associated with avirulence to both E1 and E6. 
Association with virulence. Seventy-three genes (including 51 T3Es and seven putative T3Es) were associated with virulence (Supplementary Table S5), mainly on pepper P8 (58 genes) and P2 (22 genes), then eggplants E2 (17 genes) and E3 (11 genes), tomato T5 (9 genes), eggplants E1 (7 genes), E4 (6 genes), E6 (5 genes), and pepper P6 (4 genes). Focusing on the 37 genes with at least $50 \%$ probes (score of 0.5 in Table 5) were associated with virulence to at least one accession, highest association scores ( 1 down to 0.67 ) were observed on P8 (18 genes and one ripM fragment) and P2 (8 genes); virulence on eggplants was associated with five (E2), three (E3), two (E1 and E6), or the gene RSp0213 (E4). Some genes were associated with virulence on several accessions: BA02498 on E1-E3-P2-P6-P8; PTO7001 on E1E3-E6-P2-P8-T5; PTO3558 on E1-E3-E6-P2-P8-T5; ripA5_2 on E3-E6-P2-P8-T5; and ripE2 on E1-E3-P2-P6-P8.

Association with both avirulence and virulence. Thirty-seven genes were both associated with avirulence and virulence, but in most cases high association scores (over 50\%) were with one unique phenotype, avirulence, or virulence. Some interesting cases were observed on high association scores, several effectors being associated with avirulence to eggplant and virulence to pepper. Hence, ripP1 was associated with avirulence to both eggplants E4 and E6 and to virulence to pepper P8; and ripAZ1, avirulent to $\mathrm{E} 4$ and virulent to P8. Conversely, ripAF1 was associated with avirulence to P8 and virulence to both $\mathrm{E} 2$ and E4; RSp0213 was associated with avirulence to P8 and to virulence to E4 and P2.

From this first screening, the effectors associated with interaction (avirulence or virulence) to eggplants E6 and E1 and tomato T5 were retained for further experiments. Twenty-five T3Es and effector-like genes were thus selected (Table 6), among which were 16 avirulence-associated and nine virulence-associated genes.

The avirulence/virulence-associated effectors repertoire can be described in six distribution patterns, some of which are phylotype-specific. The $25 \mathrm{~T} 3 \mathrm{Es}$ associated with interaction to eggplants and tomato were selected based on $\mathrm{CGH}$ results, targeting specific short regions of the gene. To assess their actual presence and size within the two $R$. solanacearum strain collections ( $n=48$ ), all of these genes were PCR-amplified using consensus primers (sequences and conditions detailed in the Supplementary Table S6). From this PCR screening, it appeared that T3Es were (i) successfully amplified giving the expected gene size, (ii) not amplified despite two or three independent replications, or (iii) successfully amplified but giving a gene size different from the expected one. These different states of each effector within each strain were used to build a typology of the T3E repertoires.

Each strain was thus described by a pattern of 25 variables (gene) that may have up to six different levels: $1=$ amplified at the expected size; $2=$ not amplified, and 3 to $6=$ amplified at sizes

TABLE 4. Type III effectors (T3E) and T3E-like genes associated with avirulence on eggplant, pepper, and tomato accessions, as determined by the ratio present probes/total probes per gene in each avirulent strains panel

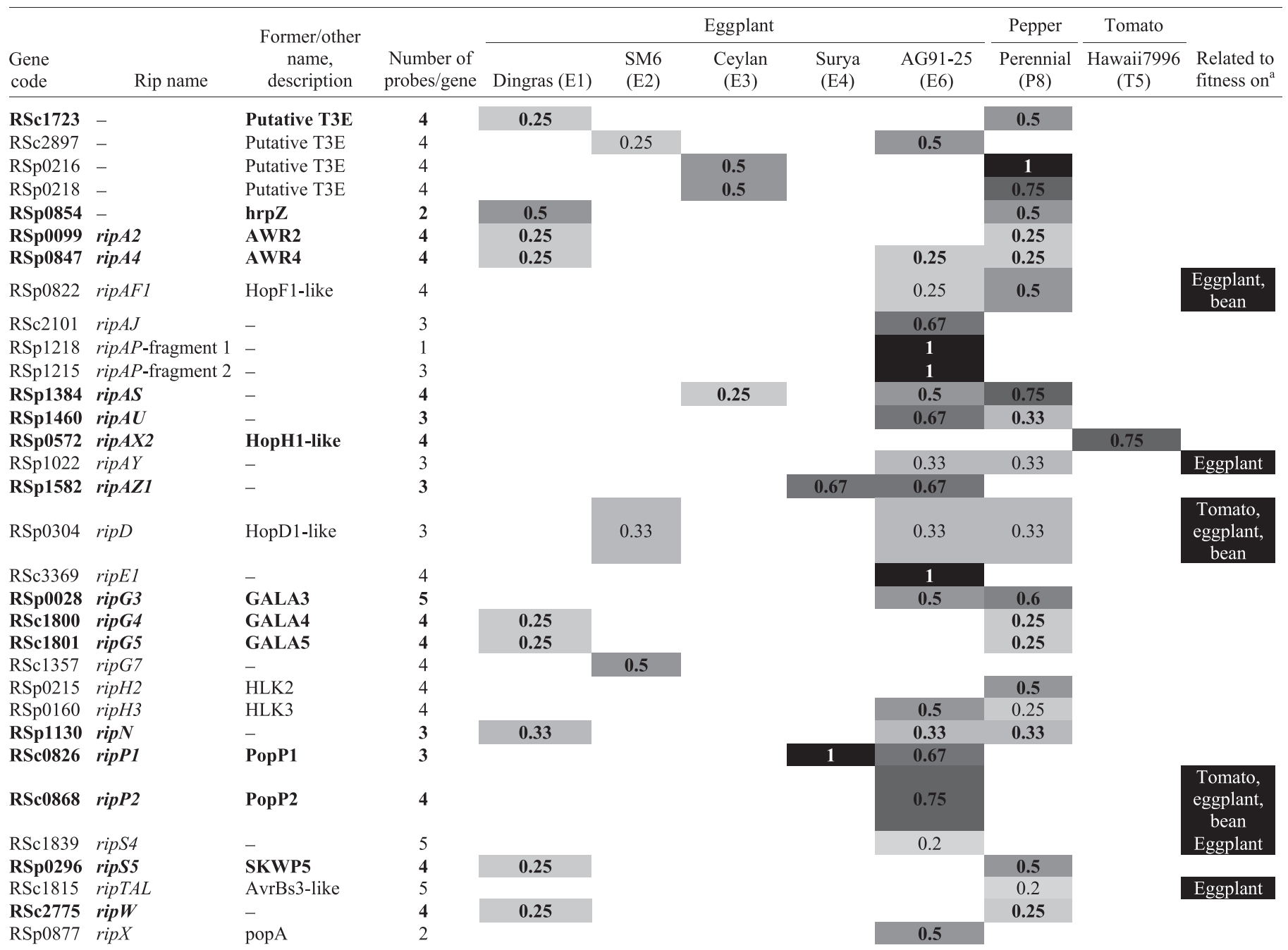

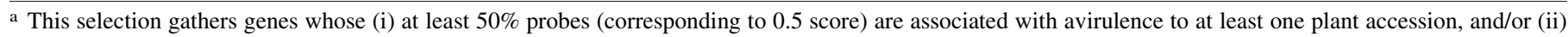
were associated with avirulence on E1 and E6, and/or (iii) significantly contributed to in planta fitness (Macho et al. 2010). Genes selected for step 2 analysis are written in bold. 
different from the expected one. The correspondences between alleles and amplicon sizes are detailed in Supplementary Table S7. The screening of the 25 T3Es in the two $R$. solanacearum strain collections thus led to the identification of six main groups of strains sharing similar T3E repertoire patterns, thus named type III effector repertoire groups (TRG) (Table 7). The catdes function (Husson et al. 2009) allowed identifying the variables' levels best describing each TRG (Supplementary Table S8). These TRG seem to be phylotype-specific, except for TRG3 and TRG6. The TRG1 gathered strains of phylotype IIB, and was best characterized by BA02498 presence (allele 1) and the absence of ripG3, ripS5, and ripP2 $\left(P\right.$ values ranging from $2.31 \times 10^{-4}$ to $\left.9.54 \times 10^{-3}\right)$. TRG2 gathered phylotype IIA strains and was best characterized by BA07003-allele 3 and the presence of ripAS (allele 1) ( $P$ values ranging from $2.66 \times 10^{-3}$ to $2.63 \times 10^{-2}$ ). TRG3 was dominated by phylotype IIB strains $(n=25)$ and was best characterized by RipG3-allele 4 and the presence of PTO1265, ripV2, and BA07003 (allele 1) and the absence of RipN and ripAS $\left(P\right.$ values ranging from $9.86 \times 10^{-13}$ to $\left.3.31 \times 10^{-8}\right)$. TRG4 contained $80 \%$ of phylotype III strains and was best characterized by RipG3-allele 3, ripW-allele 4, and ripAUallele 1 and the absence of rip $U$, PTO3558, and BA07003 ( $P$ values ranging from $2.38 \times 10^{-8}$ to $\left.7.96 \times 10^{-6}\right)$. TRG5 only contained phylotype I strains and was best described by the presence of ripG3 (allele 1), ripW-allele 3, ripG4, ripAZ1, and ripS5 and the absence of BA07003 ( $P$ values ranging from $3.50 \times 10^{-6}$ to $\left.2.45 \times 10^{-4}\right)$. TRG6, containing only RUN0930 (phylotype I) and RUN0657 (phylotype III), was characterized by ripG3-allele 5 and PTO1265-allele 3 ( $P=0.042$ for both).

The TRG representatives display high variability in virulence and aggressiveness on eggplants and tomato. To test the hypothesis that the $\mathrm{T} 3 \mathrm{E}$ repertoire may explain the virulence phenotype, we selected 11 strains representative of the six TRG to challenge the resistant tomato and eggplant accessions. Considering both T3E content and phylogenetic position (phylotype/clade/sequevar), we thus chose (i) RUN0017 (IIB/clade 4/sequevar 4NPB) to represent TRG1, (ii) RUN0058 (IIA/clade 2/sequevar 39) for TRG2, (iii) RUN0059, RUN0147, RUN0928, and RUN0941 (all in IIB/clade 5/sequevar 1) for TRG3, (iv) RUN0145 and RUN0523 (both in phylotype III/clade 6/sequevar 29 and 19, respectively) for TRG4, (v) RUN0054 (the reference GMI1000) and RUN0157 (both in phylotype I/clade 1/sequevars 18 and 15, respectively) for TRG5; and (vi) RUN0657 (III/clade 6/sequevar 19) for TRG6.

The strains were inoculated in two sets at different dates, with RUN0017 inoculated on both dates as a control. Because the wilting

TABLE 5. Type III effectors (T3E) and T3E-like genes associated with virulence on eggplant, pepper and tomato accessions, as determined by the ratio present probes/total probes per gene in each virulent strains panel ${ }^{\mathrm{a}}$

\begin{tabular}{|c|c|c|c|c|c|c|c|c|c|c|c|c|}
\hline \multirow[b]{2}{*}{$\begin{array}{l}\text { Gene or } \\
\text { probe }\end{array}$} & \multirow[b]{2}{*}{$\begin{array}{l}\text { Rip } \\
\text { Name }\end{array}$} & \multirow[b]{2}{*}{$\begin{array}{c}\text { Former/other name, } \\
\text { description }\end{array}$} & \multirow[b]{2}{*}{$\begin{array}{l}\text { Number of } \\
\text { probes/gene }\end{array}$} & \multicolumn{5}{|c|}{ Eggplant } & \multicolumn{3}{|c|}{ Pepper } & \multirow{2}{*}{$\begin{array}{c}\text { Tomato } \\
\text { Hawaii7996 } \\
\text { (T5) }\end{array}$} \\
\hline & & & & $\begin{array}{l}\text { Dingras } \\
\text { (E1) }\end{array}$ & $\begin{array}{l}\text { SMA6 } \\
\text { (E2) }\end{array}$ & $\begin{array}{l}\text { Ceylan } \\
\text { (E3) }\end{array}$ & $\begin{array}{l}\text { Surya } \\
\text { (E4) }\end{array}$ & $\begin{array}{l}\text { AG91-25 } \\
\text { (E6) }\end{array}$ & $\begin{array}{l}\text { PM687 } \\
\text { (P2) }\end{array}$ & $\begin{array}{l}\text { CA8 } \\
\text { (P6) }\end{array}$ & $\begin{array}{l}\text { Perennial } \\
\quad(\mathrm{P} 8)\end{array}$ & \\
\hline BA02498 & - & $\begin{array}{l}\text { CPUF, AvrPtoB-like } \\
\text { domain }\end{array}$ & 3 & 1 & & 1 & & & 1 & 1 & 1 & \\
\hline BA07003 & - & Pcad2 & 2 & 0.5 & & 0.5 & & & 0.5 & 0.5 & 1 & \\
\hline PT00619 & - & $\begin{array}{l}\text { Putative } \\
\text { glycosyltransferase }\end{array}$ & 2 & & & & & & & & 0.5 & \\
\hline PT01265 & - & CPUF & 3 & 0.33 & 0.33 & 0.33 & & 0.33 & 0.67 & & 0.33 & 0.33 \\
\hline РT03045 & - & CPUF (TPR domain) & 2 & & & & & & & & 1 & \\
\hline PT03558 & - & (RRSL_04659) & 3 & 0.33 & & 0.33 & & 0.33 & 0.33 & & 0.67 & 0.33 \\
\hline РT04098 & - & $\begin{array}{l}\text { Putative T3E } \\
\text { (RALIP_4318) }\end{array}$ & 3 & & & & & & & & 1 & \\
\hline РT04281 & - & Cpuf & 3 & & & & & & & & 1 & \\
\hline РT04284 & - & $\begin{array}{l}\text { Putative T3E } \\
\text { (RALIP_4533) }\end{array}$ & 2 & & & & & & & & 1 & \\
\hline PT07000 & - & $\begin{array}{l}\text { Putative T3E } \\
\text { RALIP_1709) }\end{array}$ & 3 & & & & & & 0.67 & & & \\
\hline PT07001 & - & $\begin{array}{l}\text { Putative T3E (ripM } \\
\text { fragment) }\end{array}$ & 2 & 1 & & 1 & & 1 & 1 & & 1 & 1 \\
\hline $\mathrm{RSc} 2131$ & - & Puf & 3 & & 0.67 & & & & 0.33 & & 0.33 & \\
\hline $\mathrm{RSc} 3174$ & - & Putative T3E & 4 & & & & & & 1 & & & \\
\hline RSp0213 & - & Putative T3E & 2 & & & & 1 & & 1 & & & \\
\hline $\mathrm{RSc} 2139$ & ripAl & Awr1 & 4 & & 0.75 & & & & & & & \\
\hline PT01391 & ripA5_2 & Awr5-2 (RALIP_1563) & 3 & & & 1 & & 1 & 1 & & 1 & 1 \\
\hline $\mathrm{RSc} 0321$ & $\operatorname{rip} A E$ & - & 4 & & & & & & & & 0.75 & \\
\hline RSp0822 & rip $A F 1$ & Hopf1-like & 4 & & 0.5 & & 0.5 & & & & & \\
\hline RSc0895 & ripAH & - & 3 & & 0.67 & & & & & & & \\
\hline $\mathrm{RSc} 2359$ & rip $A K$ & - & 4 & & 0.5 & & & & & & & \\
\hline RSp1582 & $\operatorname{rip} A Z 1$ & - & 3 & & & & & & & & 0.67 & \\
\hline РT04502 & ripBH & RALIP_4767 & 3 & & & & & & & & 1 & \\
\hline РT04434 & ripBI & RALIP_4696 & 3 & & & & & & & & 1 & \\
\hline RSp1239 & ripCl & - & 4 & & 0.25 & & & & 0.25 & & 0.75 & \\
\hline PT04834 & ripE2 & RALIP_0863 & 4 & 0.5 & & 0.5 & & & 0.75 & 0.5 & 0.5 & \\
\hline RSp0914 & rip $G 1$ & Gala1 ${ }^{-}$ & 3 & & 0.67 & & & & 0.33 & & & \\
\hline RSc 1800 & $\operatorname{rip} G 4$ & Gala4 & 4 & & & & & & & & 0.5 & 0.25 \\
\hline RSc1356 & rip G6 & Gala6 & 4 & & & & & & & & 0.5 & \\
\hline RSc2132 & ripJ & - & 3 & & & & & & & & 1 & \\
\hline $\mathrm{RSc} 0826$ & ripP1 & Popp1 & 3 & & & & & & & & 1 & \\
\hline $\mathrm{BA} 00250$ & ripS4 & RCFBP_11536 & 3 & & & & & & & & 0.67 & \\
\hline RSc1839 & ripS4 & Rsc1839 & 5 & & & & & & & & 0.4 & \\
\hline $\mathrm{RSc} 3212$ & ripT & - & 2 & & & & & & 0.5 & & & \\
\hline RSc1815 & $\operatorname{rip} T A L$ & - & 5 & & 0.6 & & & & & & 0.2 & \\
\hline PT03560 & $\operatorname{rip} U$ & RRSL_04660 & 2 & & & & & & & & 1 & 0.5 \\
\hline RSp1212 & ripU & - & 5 & & & & & & 0.8 & & & \\
\hline PT01326 & rip V2 & RALIP_1493 & 3 & & & & & & & & 1 & 0.33 \\
\hline
\end{tabular}

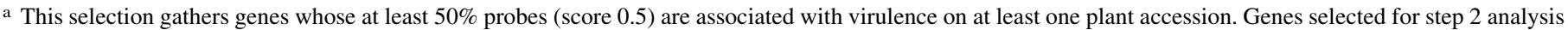
are represented in bold. 
incidence, colonization index, and AUDPC were found not to be significantly different across the two dates $(P=0.143,0.082$, and 0.615 , respectively), we pooled the two sets in one. After 28 days of incubation, the control susceptible accessions were significantly more diseased than the resistant accessions (detailed results are shown in Supplementary Fig. S1). However some strains induced few symptoms on the susceptible controls. RUN0523 (TRG4) induced less than 20\% wilt and colonization on T10 and E8 and was thus regarded a poorly aggressive strain on eggplant and tomato. RUN0058 (TRG2) induced a low wilting incidence but more than $60 \%$ colonization to T10. All the other strains induced more than $70 \%$ wilt and 80\% colonization. On eggplant E8, strains RUN0017 (TRG1), RUN0059 and RUN0928 (TRG3), RUN0523 (TRG4), and RUN0657 (TRG6) caused less than 20\% wilt and colonization; highest aggressiveness (more than $80 \%$ wilt and colonization) was observed for RUN0157 (TRG5), RUN0147, and RUN0941 (TRG3). The resistant eggplant E1 showed the highest resistance level since only RUN0147 induced more than 20\% wilt on it. The accession E6 was susceptible (30\% wilt and $60 \%$ colonization or above) to TRG3 strains RUN0147, RUN0928, and RUN0941, and to TGR5 strain RUN0157. The resistant tomato T5 was most highly affected $(80 \%$ wilt and colonization or above) by TRG3 strains RUN0147, RUN0941, and RUN0928, and by RUN0017 (TRG1). Incompatible interactions (no wilt and no colonization) were observed on the couples (i) E1 $\times$ RUN0523 and E1 $\times$ RUN0058, and (ii) E6 $\times$ RUN0054, E6 × RUN0523, E6 × RUN0145, and E6 × RUN0059.

The T3E repertoire is not globally descriptive of the virulence phenotype. The hierarchical ascending classification of the 11 strains representative of the six TRG built based on their T3E repertoire did not clearly match with their virulence phenotypes on eggplant and tomato (Fig. 2). More precisely, strains RUN0058 (TRG2) and RUN0017 (TRG1), despite having very similar T3E repertoires, highly differed in virulence on the five cultivars. Similarly, RUN0147 and RUN0059 belong to the same TRG3 but the former is highly virulent on E6 and T5, whereas the latter is avirulent on E6 and poorly aggressive on T5. The strains RUN0157 and RUN0054, though gathered in the same TRG5, greatly differ in virulence on the resistant accession E6 (Fig. 2).
From these results, we concluded that the entire T3E repertoire does not determine the phenotype of a strain.

Some T3Es are individually highly associated with avirulence or virulence. We performed a principal component analysis based on the presence or absence of genes, regardless of their allelic state. Projecting the phenotypic classes ( 0 to 5$)$ and the gene presence on the same factorial plan, we considered that genes projected in the same zone as extreme phenotypes (avirulence, coded as 0 ; virulence; coded as 3 for E1, or 4 and 5 for E6 and T5) were associated with this phenotype. On eggplant E1, the two axes opposed avirulent strains (bottom left) to virulent strains (top right) (Fig. 3A). RipA5_2 (PTO1391) was associated with virulence, whereas ripAS (RSp1384), and more secondarily ripN (RSp1130), were associated with avirulence. On eggplant E6 (Fig. 3B), avirulent strains were in the top left quarter of the plan, whereas virulent strains were in the top right and bottom left quarters. PTO3558 and ripU (PTO3560), more secondarily ripA5_2 (PTO1391), were associated with virulence, while ripP2 (RSc0868), ripAU (RSp1460), and ripG3 (RSp0028), and more secondarily ripAX2 (RSp0572) and ripP1 (RSc0826), were associated with avirulence. On tomato T5 (Fig. 3C), the phenotypes were mainly separated along the first axis, from quasi-avirulent strains on the left to virulent strains on the right. RipV2 (PTO1326), BA07003, PTO3558, and ripU (PTO3560) were associated with virulence, whereas RipP1 (RSc0826), RipN (RSp1130), ripAX2 (RSp0572), and more secondarily ripP2 (RSc0868), ripG3 (RSp0028), RipAU (RSp1460), and ripG5 (RSc1801) were associated with avirulence.

Then, we followed a stringent approach, hypothesizing that the phenotype could be explained by the presence or absence of key T3Es. For each resistant cultivar, we identified T3Es called (i) virulence effectors that were present in virulent strains and absent in avirulent strains, and (ii) avirulent effectors that were absent in virulent strains and present in avirulent strains. We thus identified the following effectors as highly associated with strain phenotypes (Table 8): ripA5_2 was associated with virulence on both eggplant E1 and tomato T5; ripE2, but also PTO1265 and PTO7001 were associated with virulence on eggplant E1; PTO3558 and ripU associated

TABLE 6. Type III effectors and effector-like genes selected on basis of their association with phenotype (avirulence or virulence) to eggplants E1 and E6 and tomato T5 following step $1^{\mathrm{a}}$

\begin{tabular}{|c|c|c|c|c|c|c|c|c|c|c|}
\hline \multirow[b]{2}{*}{ Gene Code } & \multirow[b]{2}{*}{ Rip name/other name } & \multicolumn{5}{|c|}{ Eggplant } & \multicolumn{3}{|c|}{ Pepper } & \multirow{2}{*}{$\frac{\text { Tomato }}{\mathrm{T} 5}$} \\
\hline & & $\mathrm{E} 1$ & $\mathrm{E} 2$ & E3 & $\mathrm{E} 4$ & E6 & $\mathrm{P} 2$ & P6 & $\overline{\mathrm{P} 8}$ & \\
\hline BA02498 & - & $\mathrm{V}$ & - & $\mathrm{V}$ & - & - & $\mathrm{V}$ & $\mathrm{V}$ & $\mathrm{V}$ & - \\
\hline BA07003 & - & V & - & V & - & - & $\mathrm{V}$ & V & V & - \\
\hline PT03558 & - & V & - & V & - & V & V & - & $\mathrm{V}$ & V \\
\hline РT07001 & - & $\mathrm{V}$ & - & $\mathrm{V}$ & - & $\mathrm{V}$ & $\mathrm{V}$ & - & $\mathrm{V}$ & $\mathrm{V}$ \\
\hline RSc1723 & - & A & - & - & - & - & - & - & A & - \\
\hline RSp0847 & ripA4 & A & - & - & - & A & - & - & A & - \\
\hline РT01391 & ripA5_2 & - & - & $\mathrm{V}$ & - & $\mathrm{V}$ & $\mathrm{V}$ & - & V & V \\
\hline RSp1384 & ripAS & A & - & A & - & A & - & - & A & - \\
\hline RSp1460 & ripAU & - & - & - & - & A & - & - & A & - \\
\hline RSp0572 & ripAX2 & - & - & - & - & - & - & - & - & A \\
\hline RSp1582 & ripAZ1 & - & - & - & A & A & - & - & - & - \\
\hline PT04834 & ripE2 & V & - & $\mathrm{V}$ & - & - & $\mathrm{V}$ & V & V & - \\
\hline $\mathrm{RSc} 0868$ & ripP2 & - & - & - & - & A & - & - & - & - \\
\hline RSp0296 & ripS5 & A & - & - & - & - & - & - & A & - \\
\hline РT03560 & ripU & - & - & - & - & - & - & - & $\mathrm{V}$ & V \\
\hline РT01326 & ripV2 & - & - & - & - & - & - & - & V & V \\
\hline $\mathrm{RSc} 2775$ & ripW & A & - & - & - & - & - & - & A & - \\
\hline
\end{tabular}

a Phenotypes: A, avirulence; V, virulence. 
with virulence to both E6 and T5; and BA7003 was associated with virulence to tomato $\mathrm{T} 5$. ripAS was associated with avirulence to $\mathrm{E} 1$, ripP2 and ripAX2 to avirulence on $\mathrm{E} 6$; and $\operatorname{rip} P 1$, ripP2, ripAX2, ripN, and ripS5 were associated with avirulence to T5.

\section{DISCUSSION}

Although bacterial wilt has been a major biotic stress in solanaceous crops throughout the world, knowledge remains scarce about the plant genes allowing hosts to resist $R$. solanacearum attacks, and about the bacterial genes most contributing to adaptation to new host or to a resistant accession. To prime the development of durable resistance sources, given the huge genomic and phenotypic plasticity of the pathogen, it is now critical to favor pathogen-informed resistance breeding. Such a strategy requires identifying the bacterial genes involved in virulence to hosts and selected for that function, as well as those counter-selected based on detection in resistant hosts, for further exploring their diversity and evolutionary dynamics in natural populations. Studies on $R$. solanacearum-plant interactions have been focused for a long time on the model species Arabidopsis thaliana (Deslandes et al. 1998, 2003; Digonnet et al. 2012) and Medicago truncatula (Ben

TABLE 7. Distribution of the 25 type III effectors (T3E) and T3E-like genes selected among Ralstonia solanacearum strains from Core-RS2 and Reunion Island, as determined by polymerase chain reaction (PCR) amplifications ${ }^{\mathrm{a}}$

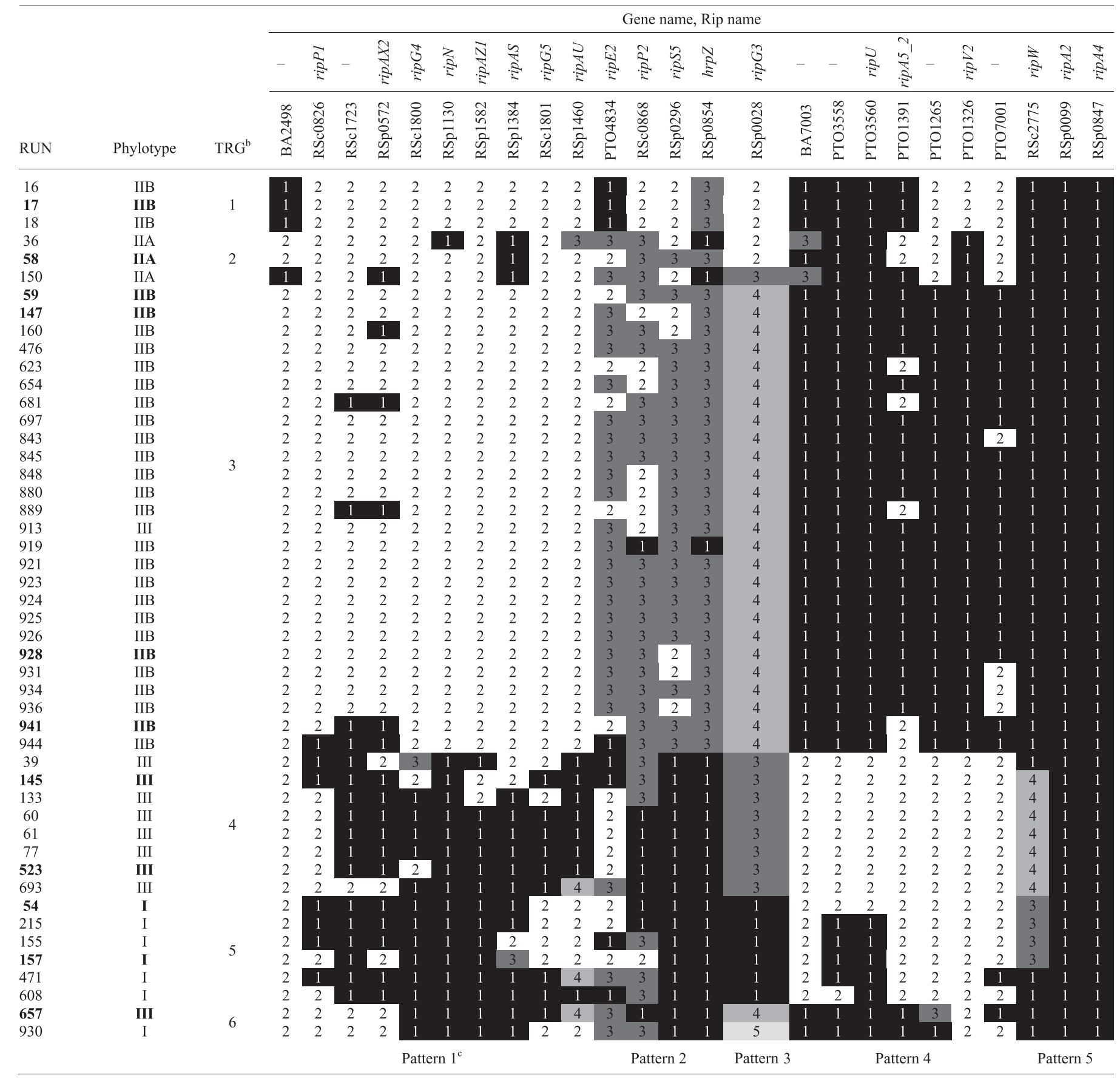

a Genes were either amplified at the expected size (allele 1), or not amplified (allele 2). In this latter case, absence of amplification may be interpreted as absence of the gene, or high divergence in the region targeted by the PCR primers. Genes were also amplified at a different size than expected (alleles 3, 4, and 5). Gene typology led to identify six T3E repertoire groups (TRG) within which were chosen representative strains (written in bold) to be inoculated on eggplant and tomato.

b Type III effector repertoire group, determined using the ascending hierarchical classification (function agnes, package cluster) with strains as individuals and genes as variables.

c Pattern, determined using the ascending hierarchical classification (function agnes, package cluster) with genes as individuals and strains as variables. 
et al. 2013; Turner et al. 2009; Vailleau et al. 2007), but transposition of these findings to crops has been problematic. Some critical mechanistic differences having been identified between pathogenesis to model species on one hand and to crops on the other hand (Lin et al. 2008; Remigi et al. 2011). Deciphering plant-microbe interactions on crop species is thus essential.

Our three-step association genetics approach constituted a first published snapshot of the type III effector diversity existing in natural plant-associated $R$. solanacearum populations, and allowed us to identify avirulence and virulence candidate genes. Because population structure can cause bias in the association with phenotype (Falush and Bowden 2006), we checked using $\chi^{2}$ test that there was no correlation between the phylotype and the effector presence.

A first snapshot of the T3E distribution in a large natural collection. This study gives a different view of the core-effectome within the $R$. solanacearum species complex (RSSC [Genin and Denny 2012]). The core-RS2 core-effectome contains 40 T3Es, which does not completely match the core-effectome identified by Peeters et al. (2013). Hence, the Peeters's core-effectors ripAO, ripE1, and ripG7 were present in $90 \%$ core-RS2 strains; the core ripAC was present in $80 \%$ core-RS2 strains, and the core ripAA was even more variable, being absent from the phylotype III strains (except CMR15) and from two phylotype I strains, PSS366 and PSS358. The core rip $C 1$ and rip $U$ were also variable in our study, but we observed a discrepancy between our results and Peeters' results on CMR15. This absence in our data set may be explained by technical artifacts. Recent genomics studies focusing on phylotype II genomes identified core-effectomes of different composition, including either 14 T3Es (Ailloud et al. 2015) or 31 T3Es (Clarke et al. 2015). Our own analysis on publicly available genomes identified 11 core-effectors on a quite phylogenetically unbalanced data set. Additional genomic sequences, especially within phylotype III, are needed to approach the actual composition of the RSSC core-effectome.

The T3E repertoires from the Reunion collection should be regarded partial since 25 T3Es only were considered, but they still give interesting insights on the prevalence and diversity of these effectors. Effector distribution could indeed be described in six patterns (TRG) based on effector presence but also alleles. The most polymorphic effector was ripG3, whose alleles were major descriptors of the different TRGs: allele 1 for TRG5, allele 3 for TRG4, allele 4 for TRG3, and allele 5 for TRG6 (Table 7). Such diversity may be a signature of the diversifying selection evoked for this gene in the reference paper describing the GALA family evolution (Remigi et al. 2011).

Some effectors were present throughout the collection, like ripA2, ripA4, and ripW (pattern 5 in Table 7). ripA2 and ripA4 were monomorphic, but it is important to note that these were partial sequences (3,065 bp over the 3,381 bp of ripA2 ${ }_{G M I 1000}$, and the 960 -bp region of the 3,990-bp ripA4 $4_{G M I 1000}$ ). Whereas ripA2 (formerly AWR2) was primarily characterized as contributing to virulence (Sole et al. 2012), it could be successfully amplified in the T5-avirulent strains. This difference could be due to sequence polymorphism or functional redundancy; it also may indicate that ripA2 plays a dual role within tomato, supporting the Invasion Model (Cook et al. 2015). Whereas, ripW (formerly called pop W) gave three different alleles: one being widespread in the collection $(1,202 \mathrm{bp}$ with IIB primers and 1,119 bp with GMI1000 primers), another (allele 4: 1,202 bp with IIB primers only) being specific to TRG 4, composed of phylotype III strains, and a third one (allele 3: 1,119 bp with GMI1000 primers only) specifically found in TRG5 (phylotype I strains). We did not find correlation between these alleles and an avirulence phenotype. rip $W$ was previously characterized as a twodomain protein ( $\mathrm{Li}$ et al. 2010), whose harpin activity (detected on tobacco) resides in its $\mathrm{N}$-terminal domain (first 159 residues), and which doesn't significantly contribute to virulence on tomato. The analysis of a 20 -strain collection, covering six countries but whose phylotypes were not determined, allowed the identification of six alleles ranging from 1,131 to $1,155 \mathrm{bp}$. The range of variation that we observed was thus higher, and it may be interesting to determine the critical residues involved in the harpin activity on tobacco and solanaceous.

An approach with rich outputs, but with some limitations. Although most of the associations detected in step 3 were consistent with those found in step 1 , some distortions should be evoked and discussed. Indeed, ripAP, ripE1, and ripAJ, though associated with avirulence to E6 from step 1 (Table 5), were not retained in the downstream analyses. RipAP is present in two fragments in the GMI1000 genome, and experiments established that it is not secreted by the T3SS (A. C. Cazalé and N. Peeters, personal communication 2014). Moreover, the associations found in step 1 were not always confirmed in STEP 3 (Table 9). Main discrepancies concerned avirulence to Hawaii7996 (T5): several associations found on full-length gene analysis (for $\operatorname{rip} A U$, $\operatorname{rip} G 3, \operatorname{ripN}, \operatorname{rip} P 1$ and $\operatorname{rip} P 2$, ripG5, and $\operatorname{ripS5)}$ were not primarily detected from probe data analysis. Avirulence to eggplant detected in step 1 was mostly confirmed in step 3, with some exceptions. The E6-avirulence of RipAX2 was found only in step 3, whereas this of ripN was not confirmed in step 3; ripAS, primarily associated with avirulence on E3 and E6, was found avirulent to E1 only from $\mathrm{S}$ step 3 . Regarding virulence effectors, the virulence of ripE2 on E1, ripA5_2 on E6, and ripV2 on T5, were confirmed, whereas ripU, virulent to T5 from step 1, was found virulent to T5 but also E6 in step 3. It is thus strongly recommended to combine both approaches and to favor fulllength gene analysis for the choice of candidate genes.

Avirulence and virulence phenotypes are not explained by repertoires, but rather by individual effectors which constitute promising candidates interacting with eggplant and tomato. Strains of identical phylotype and TRG displayed very different virulence phenotypes (see RUN0054 and RUN0157 as an example), whereas other strains displaying identical phenotypes were in different TRG (see RUN0157 [TRG5] and RUN0941 [TRG3]). The "repertoire-for-repertoire" hypothesis, stated to

TABLE 8. Type III effectors (T3E) highly associated with strain phenotypes on the three resistant accessions

\begin{tabular}{|c|c|c|c|}
\hline Plant accession & & Strain (RUN) & Associated $\mathrm{T} 3 \mathrm{E}^{\mathrm{a}}$ \\
\hline \multirow{6}{*}{$\begin{array}{l}\text { Dingras multiple } \\
\text { Purple (E1) }\end{array}$} & \multirow[t]{4}{*}{ Virulent strains } & 147 & ripA5_2 (PTO1391) \\
\hline & & 941 & PTO $1 \overline{2} 65$ \\
\hline & & 17 & PTO7001 \\
\hline & & & ripE2 (PTO4834) \\
\hline & \multirow[t]{2}{*}{ Avirulent strains } & 523 & $\operatorname{ripAS}\left(\operatorname{RSp}_{1384}\right)^{\mathrm{b}}$ \\
\hline & & 58 & \\
\hline \multirow[t]{7}{*}{ AG91-25 (E6) } & \multirow[t]{3}{*}{ Virulent strains } & 941 & PTO3558 \\
\hline & & 157 & $\operatorname{ripU}(\mathrm{PTO} 3560)$ \\
\hline & & 147 & \\
\hline & \multirow[t]{4}{*}{ Avirulent strains } & 523 & ripP2 (RSc0868) \\
\hline & & 145 & ripAX2 (RSp0572) \\
\hline & & 59 & \\
\hline & & 54 & \\
\hline \multirow[t]{9}{*}{ Hawaii7996 (T5) } & \multirow[t]{4}{*}{ Virulent strains } & 941 & PTO3558 $^{c}$ \\
\hline & & 147 & ripU (PTO3560) \\
\hline & & 17 & BA7003 \\
\hline & & & ripA5_2 (PTO1391) \\
\hline & \multirow{5}{*}{$\begin{array}{l}\text { Quasi-avirulent } \\
\text { strains }^{\mathrm{d}}\end{array}$} & 145 & ripP1 (RSc0826) \\
\hline & & & ripAX2 (RSp0572) \\
\hline & & & ripP2 (RSc0868) \\
\hline & & 54 & $\operatorname{ripN}(\mathrm{RSp} 1130)$ \\
\hline & & & ripS5 (RSp0296) \\
\hline
\end{tabular}

a The T3Es associated with virulence were absent in all avirulent strains and present in all but one virulent strains, whereas those associated with avirulence were absent in all virulent strains and present in all but one avirulent strains.

b The avirulence T3Es marked in bold were absent in all virulent strains and present in all avirulent strains.

c The virulence T3Es marked in bold were present in all virulent strains and absent in all avirulent strains.

d The quasi-avirulent strains induced no wilt, but were able to colonize Hawaii7996, corresponding a virulence phenotype of 1 instead of 0 . 
explain the Xanthomonas host specificity (Hajri et al. 2009), does not match the $R$. solanacearum situation.

Collectively, the final principal component analysis and the stringent analysis have helped to define a short list of avirulenceand virulence-associated effectors to be further investigated.
Among avirulence effectors, ripP2 is one of the best candidates, associated with both eggplant E6 and tomato T5. Then, follow ripAU and ripG3, as well as ripP1 and ripAX2 (also for avirulence to E6 and T5). Then we identify ripN (avirulence to E1 and T5) and ripAS (avirulence to E1 only). Since ripG5 is only associated with

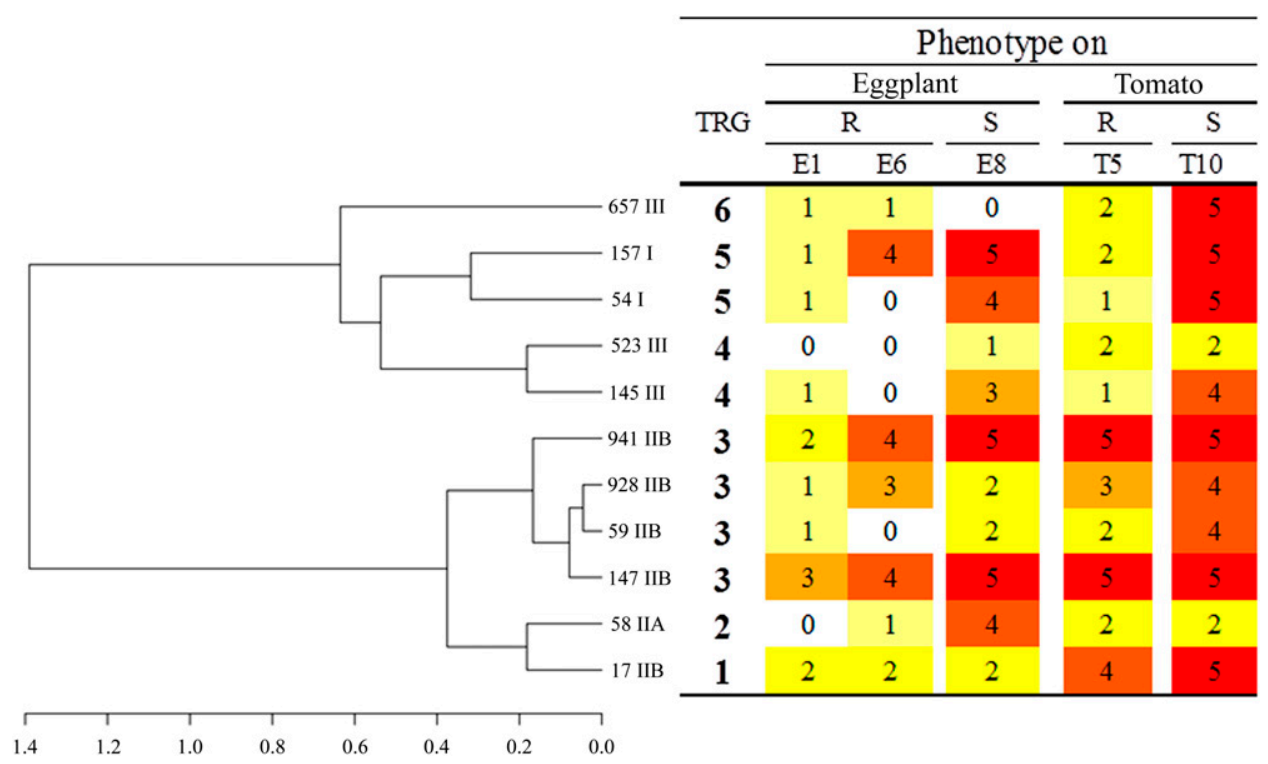

Fig. 2. Type III effector (T3E) genotypes do not match virulence phenotypes. Hierarchical ascending classification of Ralstonia solanacearum strains (named by their RUN number and phylotype) based on their T3E repertoire, and correspondence with phenotypes observed on resistant (R) and susceptible (S) eggplants and tomatoes. TRG, type III effector repertoire group. The phenotype score was defined by the combination of final wilting incidence and colonization index, and calculated following Lebeau et al. (2011), where $0=$ complete resistance (no wilt and no colonization), $1=$ highly resistant, $2=$ moderately resistant, $3=$ partially resistant, $4=$ moderately susceptible, and $5=$ highly susceptible.
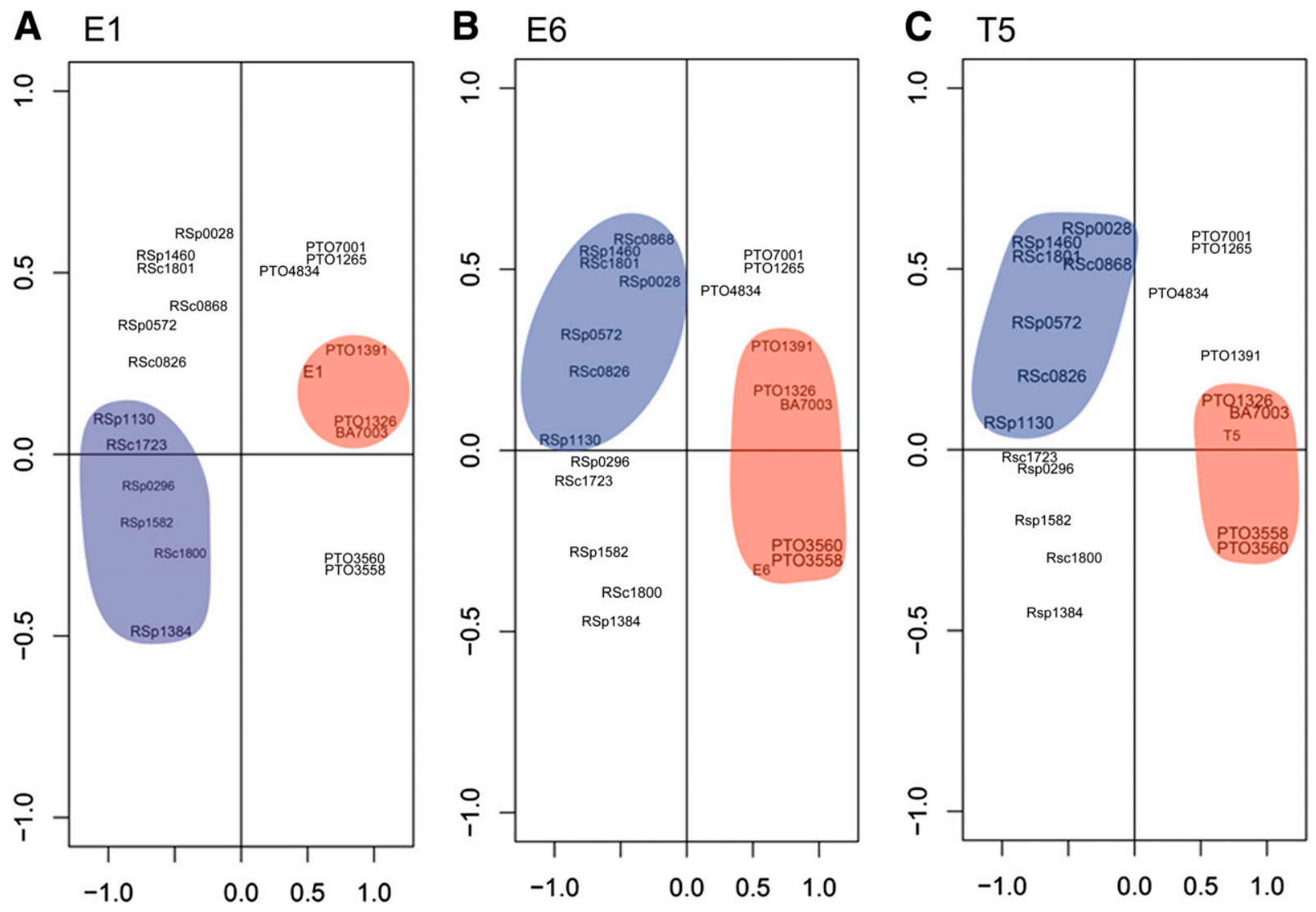

Fig. 3. Distribution of the type III effector (T3E) genes on the factorial plan of the two mostly informative axes of the principal component analysis performed on gene presence-absence data and phenotypic data collected from pathogenicity tests on A, Dingras multiple Purple (E1), B, AG91-25 (E6), and C, Hawaii7996 (T5). T3E genes associated with avirulence are shaded in blue, while those associated with virulence are shaded in red. 
avirulence to T5, and because it is expressed in operon with ripG4, we chose not to keep it on our short list.

Among virulence effectors, most promising candidates are PTO3558 and ripU (virulence to both E6 and T5), ripA5_2 (virulence to both E6, E1, and T5), and then ripV2 and BA07003 (virulence to T5). It will be critical first to check the expression and secretion of PTO3558 and BA07003 by the T3SS. This short list of effectors is now nominated for further experiments that may validate their avirulence or virulence function.

ripP2 (former popP2) has been the first described $R$. solanacearum avirulence gene to interact with the RRS1-R gene, carried by the Arabidopsis thaliana accession Nd1 (Deslandes et al. 2003), whose functions have been most thoroughly investigated (see the review of Deslandes and Genin [2014] as well as Le Roux et al. [2015] and Sarris et al. [2015]). Amplifying the 8-to-989-bp region (over 1,464 bp in total), we identified two alleles: 982 bp (allele 1) found within almost all phylotype III strains and two phylotype I strains (RUN0054 and RUN0215), and 950 bp (allele 3) found in most phylotype IIA and IIB strains, three phylotype III strains (RUN0039, RUN0145, and RUN0133), and two phylotype I strains (RUN0155, RUN0471). To our knowledge, this is the first published paper describing ripP2 diversity. Whether these ripP2 alleles keep their enzymatic functions and their ability to be detected within plant (their "invasion pattern" sensu Cook et al. [2015]) remains to be tested (Tasset et al. 2010). It is now tempting to speculate that the interaction eggplant AG91-25/ripP2 may follow the Arabidopsis RRS1-R/ripP2 model (Bernoux et al. 2008; Deslandes et al. 1998, 2002, 2003; Le Roux et al. 2015; Sarris et al. 2015). According to this model, the AG91-25 major resistance gene ERsl (Lebeau et al. 2013) could be homologous of RRS1-R, or coupled to an RPS4 homolog. However, preliminary BLAST search of RRS1-R on the eggplant sequence genome (Hirakawa et al. 2014) returned no hit (S. Salgon and C. Sauvage, personal communication 2015). Recently, ripP2 was demonstrated to specifically interact with a new eggplant resistance protein, RE-BW (Xiao et al. 2014); it remains to be determined whether this gene colocalizes with ERs1.

ripAX2, also called rip36 (Peeters et al. 2013; Poueymiro and Genin 2009), codes for the other demonstrated avirulence effector, eliciting HR on Solanum torvum (Nahar et al. 2014), a wild relative of eggplant. This paper gives first insights on the diversity on this poorly known effector, whose prevalence looks highest in phyloypes III and I strains.

ripP1 (former popP1), whose protein was demonstrated as an avirulence factor on Petunia (Lavie et al. 2002) and HR-elicitor on Nicotiana glutinosa (Poueymiro et al. 2009), was only detected in phylotypes I and III, giving a single allele of 1,088 bp (over the 1,104 bp total gene), and its presence was quite variable, even within phylotype I strains (absent in two over six strains). This variability was also reported in a Japanese phylotype I 22 strain-collection, but popPl presence was not correlated with HR on tobacco (Liu et al. 2009). Its homolog in Xanthomonas perforans, XopJ4, was also reported as avirulence protein recognized by the Solanum penelli RXopJ4 gene (Sharlach et al. 2013).

ripA5_2 (former AWR5-2) on the other hand, was not reported as a virulence effector in the literature. AWR5 was indeed recognized by Arabidopsis and induced an HR on Nicotiana tabacum (Sole et al. 2012). It remains to assess the actual expression and the respective roles of the two ripA5 paralogs in plant-pathogen interactions.

Potential candidate effectors in interaction with other species. Because the resistance levels observed were highest on eggplant, we focused our quest on this species. But scientists should also use these results to further investigate the pepper- $R$. solanacearum molecular interactions. One should focus on the role, distribution, diversity, and evolution of the two harpins, hrpZ and ripW, and the 10 effectors associated with avirulence to both eggplant and the pepper 'Perennial' (P8). Among these are two members of the ripA family (former AWR family), ripA2 and ripA4 (Sole et al. 2012), and three members for the ripG family (former GALA family), ripG3, ripG4, ripG5, whose functions remain unknown on pepper.

Furthermore, some cases of eggplant-pepper differential phenotypes may deserve further investigation. ripPl and ripAZl were associated with avirulence to eggplant 'Surya' (E4) and virulence to pepper Perennial (P8). Interestingly, this host-specific differential function has been reported for the ripP1 homolog in Xanthomonas euvesicatoria, XopJ (formerly AvrXv4), whose protein displays avirulence function on tomato (Astua-Monge et al. 2000) but virulence function on pepper, reducing the salicylic acid accumulation

TABLE 9. Correspondence between phenotype-genotype associations inferred from comparative genomic hybridization (CGH) data (step 1) and from full-length polymerase chain reaction (PCR) data (step 3) for the 25 type III effector and effector-like genes ${ }^{\mathrm{a}}$

\begin{tabular}{|c|c|c|c|c|c|c|c|}
\hline \multirow[b]{2}{*}{ Gene code } & \multirow[b]{2}{*}{ Rip name/other name } & \multicolumn{2}{|c|}{ Dingras (E1) } & \multicolumn{2}{|c|}{ AG91-25 (E6) } & \multicolumn{2}{|c|}{ Hawaii7996 (T5) } \\
\hline & & $\mathrm{CGH}$ & PCR & $\mathrm{CGH}$ & PCR & $\mathrm{CGH}$ & PCR \\
\hline BA02498 & - & $\mathrm{V}$ & - & - & - & - & - \\
\hline BA07003 & - & V & - & - & - & - & $\mathrm{V}$ \\
\hline PT03558 & - & V & - & - & V & - & V \\
\hline PT07001 & - & V & V & V & - & - & - \\
\hline RSc1723 & - & A & - & - & - & - & - \\
\hline RSp0854 & HrpZ & A & - & - & - & - & - \\
\hline PT01391 & ripA5_2 & - & V & V & V & - & $\mathrm{V}$ \\
\hline RSp1384 & $\operatorname{Rip} A \bar{S}$ & - & A & A & - & - & - \\
\hline RSp1460 & $\operatorname{Rip} A U$ & - & - & A & $\mathrm{A}$ & - & $\mathrm{A}$ \\
\hline RSp0572 & ripAX2 & - & - & - & $\mathrm{A}$ & A & $\mathrm{A}$ \\
\hline RSp1582 & ripAZl & - & - & A & - & - & - \\
\hline PT04834 & ripE2 & V & V & V & - & - & - \\
\hline RSp0028 & ripG3 & - & - & A & $\mathrm{A}$ & - & A \\
\hline RSp0296 & ripS5 & A & - & - & - & - & $\mathrm{A}$ \\
\hline PT03560 & $\operatorname{Rip} U$ & - & - & - & V & V & $\mathrm{V}$ \\
\hline PT01326 & ripV2 & - & - & - & - & V & V \\
\hline RSc2775 & RipW & A & - & - & - & - & - \\
\hline
\end{tabular}

${ }^{a}$ Phenotype-CGH associations are summarized in Table 6, whereas phenotype-PCR data associations are summarized in Table 8 and Figure 3. Genes marked in bold are identified from full-length PCR, or from both approaches. A, associated with avirulence; V, associated with virulence. 
(Ustun et al. 2013). Conversely, ripAF1 was associated with virulence to eggplants SM6 and Surya and avirulent to pepper Perennial. Again, these findings may support the view of type III effectors as dual interactors, contributing to virulence or overall bacterial fitness within a species or a species cultivar, and specifically recognized by other cultivars to trigger defense responses (Cook et al. 2015).

Future research. This study should be regarded as a first step toward decomposing the molecular bases of solanaceaous$R$. solanacearum interactions. As previously stated (Kirzinger and Stavrinides 2012), "changes in host specificity can range from the smallest to the largest genetic change," including SNPs, residue change, intragenic or total gene insertion/deletions, and gene repertoire up to genomic island. In this study, we considered only the repertoire and gene scales. Future research is now needed at the sequence level to identify regions or residues that may be critical for detection by the plant (previously named avirulence) or for its virulence function. The alleles of the effector short-list that we identified will be now monitored in natural $R$. solanacearum populations, to assess their distribution, diversity, and the type of selection they are subjected to, to complete the Clarke's inventory of conserved effectors (Clarke et al. 2015).

In future research, it will be important also to validate the avirulence function of these candidates by knock-out and gain-offunction experiments (thus following the Falush-Bowden approach [Falush and Bowden 2006]), and using complemental functional screens that will help elucidate the actual mechanism of their recognition by plants (in which organ, at which pathogenesis stage). Once such a validation is completed, future research should also focus on the plant targets of these bacterial proteins. Finally, a large field of research is open for deciphering the interaction networks (synergies, antagonisms) involving type III effectors and the architecture of Solanaceae innate immunity.

\section{ACKNOWLEDGMENTS}

This research was financially supported by the European Union (FEDER project) and the Conseil Régional de la Réunion. We thank S. Lebon, J.-M. Baptiste, and F. Maillot for their excellent technical assistance, as well as J.-J. Chéron. Ralstonia solanacearum genomic resources were accessed thank to the MAGE RalstoniaScope project directed by P. Prior.

\section{LITERATURE CITED}

Ailloud, F., Lowe, T., Cellier, G., Roche, D., Allen, C., and Prior, P. 2015. Comparative genomic analysis of Ralstonia solanacearum reveals candidate genes for host specificity. BMC Genomics 16:270.

Angot, A., Peeters, N., Lechner, E., Vailleau, F., Baud, C., Gentzbittel, L., Sartorel, E., Genschik, P., Boucher, C., and Genin, S. 2006. Ralstonia solanacearum requires F-box-like domain-containing type III effectors to promote disease on several host plants. Proc. Natl. Acad. Sci. USA 103:14620-14625.

Astua-Monge, G., Minsavage, G. V., Stall, R. E., Vallejos, C. E., Davis, M. J., and Jones, J. B. 2000. Xv4-vrxv4: A new gene-for-gene interaction identified between Xanthomonas campestris pv. vesicatoria race T3 and wild tomato relative Lycopersicon pennellii. Mol. Plant-Microbe Interact. 13:1346-1355.

Ben, C., Debelle, F., Berges, H., Bellec, A., Jardinaud, M., Anson, P., Huguet, T., Gentzbittel, L., and Vailleau, F. 2013. MtQRRS1, an R-locus required for Medicago truncatula quantitative resistance to Ralstonia solanacearum. New Phytol. 199:758-772.

Bernoux, M., Timmers, T., Jauneau, A., Briere, C., de Wit, P., Marco, Y., and Deslandes, L. 2008. RD19, an Arabidopsis cysteine protease required for RRS1-R-mediated resistance, is relocalized to the nucleus by the Ralstonia solanacearum PopP2 effector. Plant Cell 20:2252-2264.

Brown, D. G., Swanson, J. K., and Allen, C. 2007. Two host-induced Ralstonia solanacearum genes, acrA and $\operatorname{dinF}$, encode multidrug efflux pumps and contribute to bacterial wilt virulence. Appl. Environ. Microbiol. 73:2777-2786

Carmeille, A., Caranta, C., Dintinger, J., Prior, P., Luisetti, J., and Besse, P. 2006. Identification of QTLs for Ralstonia solanacearum race 3-phylotype II resistance in tomato. Theor. Appl. Genet. 113:110-121.
Chang, J. H., Desveaux, D., and Creason, A. L. 2014. The ABCs and 123s of bacterial secretion systems in plant pathogenesis. Annu. Rev. Phytopathol. $52: 317-345$

Clarke, C. R., Studholme, D. J., Hayes, B., Runde, B., Weisberg, A., Cai, R., Wroblewski, T., Daunay, M. C., Wicker, E., Castillo, J. A., and Vinatzer, B. A. 2015. Genome-enabled phylogeographic investigation of the quarantine pathogen Ralstonia solanacearum race 3 biovar 2 and screening for sources of resistance against its core effectors. Phytopathology 105:597-607.

Cook, D. E., Mesarich, C. H., and Thomma, B. P. 2015. Understanding plant immunity as a surveillance system to detect invasion. Annu. Rev. Phytopathol. 53:541-563.

Cunnac, S., Chakravarthy, S., Kvitko, B. H., Russell, A. B., Martin, G. B., and Collmer, A. 2011. Genetic disassembly and combinatorial reassembly identify a minimal functional repertoire of type III effectors in Pseudomonas syringae. Proc. Natl. Acad. Sci. USA 108:2975-2980.

Deberdt, P., Guyot, J., Coranson-Beaudu, R., Launay, J., Noreskal, M., Riviere, P., Vigné, F., Laplace, D., Lebreton, L., and Wicker, E. 2014. Diversity of Ralstonia solanacearum in French Guiana expands knowledge on the "emerging ecotype". Phytopathology 104:586-596.

Denny, T. P. 2006. Plant pathogenic Ralstonia species. Pages 573-644 in: Plant-Associated Bacteria S. S. Gnanamanickam, ed. Springer, Dordrecht, the Netherlands.

Deslandes, L., and Genin, S. 2014. Opening the Ralstonia solanacearum type III effector tool box: Insights into host cell subversion mechanisms. Curr. Opin. Plant Biol. 20:110-117.

Deslandes, L., Olivier, J., Peeters, N., and Dong, F. X., Khounlotham, M., Boucher, C., Somssich, I., Genin, S., and Marco, Y. 2003. Physical interaction between RRS1-R, a protein conferring resistance to bacterial wilt, and PopP2, a type III effector targeted to the plant nucleus. Proc. Natl. Acad. Sci. USA 100:8024-8029.

Deslandes, L., Olivier, J., Theulieres, F., Hirsch, J., Feng, D., Bittner, E. P., Beynon, J., Marco, Y., and Feng, D. 2002. Resistance to Ralstonia solanacearum in Arabidopsis thaliana is conferred by the recessive $R R S 1-R$ gene, a member of a novel family of resistance genes. Proc. Natl. Acad. Sci. USA 99:2404-2409.

Deslandes, L., Pileur, F., Liaubet, L., Camut, S., Can, C., Williams, K., Holub, E., Beynon, J., Arlat, M., and Marco, Y. 1998. Genetic characterization of RRS1, a recessive locus in Arabidopsis thaliana that confers resistance to the bacterial soilborne pathogen Ralstonia solanacearum. Mol. PlantMicrobe Interact. 11:659-667.

Digonnet, C., Martinez, Y., Denance, N., Chasseray, M., Dabos, P., Ranocha, P., Marco, Y., Jauneau, A., and Goffner, D. 2012. Deciphering the route of Ralstonia solanacearum colonization in Arabidopsis thaliana roots during a compatible interaction: Focus at the plant cell wall. Planta 236:1419-1431.

Dray, S., and Dufour, A. B. 2007. The ade4 package: implementing the duality diagram for ecologists. J. Stat. Softw. 22:1-20.

Falush, D., and Bowden, R. 2006. Genome-wide association mapping in bacteria? Trends Microbiol. 14:353-355.

Feng, F., and Zhou, J. M. 2012. Plant-bacterial pathogen interactions mediated by type III effectors. Curr. Opin. Plant Biol. 15:469-476.

Flores-Cruz, Z., and Allen, C. 2011. Necessity of OxyR for the hydrogen peroxide stress response and full virulence in Ralstonia solanacearum. Appl. Environ. Microbiol. 77:6426-6432.

Genin, S., and Denny, T. P. 2012. Pathogenomics of the Ralstonia solanacearum species complex. Annu. Rev. Phytopathol. 50:67-89.

Gonzalez, E. T., Brown, D. G., Swanson, J. K., and Allen, C. 2007. Using the Ralstonia solanacearum Tat secretome to identify bacterial wilt virulence factors. Appl. Environ. Microbiol. 73:3779-3786.

Guidot, A., Elbaz, M., Carrère, S., Siri, M. I., Pianzzola, M. J., Prior, P., and Boucher, C. 2009. Specific genes from the potato brown rot strains of Ralstonia solanacearum and their potential use for strain detection. Phytopathology 99:1105-1112.

Guidot, A., Prior, P., Schoenfeld, J., Carrere, S., Genin, S., and Boucher, C. 2007. Genomic structure and phylogeny of the plant pathogen Ralstonia solanacearum inferred from gene distribution analysis. J. Bacteriol. 189: 377-387.

Hajri, A., Brin, C., Hunault, G., Lardeux, F., Lemaire, C., Manceau, C., Boureau, T., and Poussier, S. 2009. A "repertoire for repertoire" hypothesis: Repertoires of type three effectors are candidate determinants of host specificity in Xanthomonas. PLoS One 4:e6632.

Hirakawa, H., Shirasawa, K., Miyatake, K., Nunome, T., Negoro, S., Ohyama, A., Yamaguchi, H., Sato, S., Isobe, S., Tabata, S., and Fukuoka, H. 2014. Draft genome sequence of eggplant (Solanum melongena L.): The representative solanum species indigenous to the Old World. DNA Res. 21: 649-660.

Hothorn, T., Bretz, F., and Westfall, P. 2008. Simultaneous inference in general parametric models. Biomed. J. 50:346-363.

Husson, F., Josse, J., Lê, S., and Mazet, J. 2015. FactoMineR: Multivariate Exploratory Data Analysis and Data Mining. R package version 1.29. 
$\mathrm{R}$ package. https://cran.r-project.org/web/packages/FactoMineR/index. html

Husson, F., Lê, S., and Pagès, J. 2009. Analyse de données avec R. In: Pratique de la Statistique. E. Matzner-Løber, ed. Presses Universitaires de Rennes, Rennes, France.

Jones, J. D., and Dangl, J. L. 2006. The plant immune system. Nature 444: 323-329.

Kelman, A. 1954. The relationship of pathogenicity in Pseudomonas solanacearum to colony appearance on a tetrazolium medium. Phytopatholgy 44:693-695.

Kenny, B., and Valdivia, R. 2009. Host-microbe interactions: Bacteria. Curr. Opin. Microbiol. 12:1-3.

Kirzinger, M. W., and Stavrinides, J. 2012. Host specificity determinants as a genetic continuum. Trends Microbiol. 20:88-93.

Lavie, M., Shillington, E., Eguiluz, C., Grimsley, N., and Boucher, C. 2002. PopP1, a new member of the YopJ/AvrRxv family of type III effector proteins, acts as a host-specificity factor and modulates aggressiveness of Ralstonia solanacearum. Mol. Plant-Microbe Interact. 15:1058-1068.

Le Roux, C., Huet, G., Jauneau, A., Camborde, L., Tremousaygue, D., Kraut, A., Zhou, B., Levaillant, M., Adachi, H., Yoshioka, H., Raffaele, S., Berthome, R., Coute, Y., Parker, J. E., and Deslandes, L. 2015. A receptor pair with an integrated decoy converts pathogen disabling of transcription factors to immunity. Cell 161:1074-1088.

Leach, J. E., Cruz, C. M. V., Bai, J. F., and Leung, H. 2001. Pathogen fitness penalty as a predictor of durability of disease resistance genes. Annu. Rev. Phytopathol. 39:187-224.

Lebeau, A. 2010. Résistance de la tomate, l'aubergine et le piment à Ralstonia solanacearum: Interactions entre les géniteurs de résistance et la diversité bactérienne, caractérisation et cartographie des facteurs génétiques impliqués chez l'aubergine. Ph.D. thesis. Faculté des Sciences et Technologies, Université de la Réunion, Saint Denis de la Réunion.

Lebeau, A., Daunay, M. C., Frary, A., Palloix, A., Wang, J. F., Dintinger, J., Chiroleu, F., Wicker, E., and Prior, P. 2011. Bacterial wilt resistance in tomato, pepper, and eggplant: Genetic resources respond to diverse strains in the Ralstonia solanacearum species complex. Phytopathology 101:154-165.

Lebeau, A., Gouy, M., Daunay, M., Wicker, E., Chiroleu, F., Prior, P., Frary, A., and Dintinger, J. 2013. Genetic mapping of a major dominant gene for resistance to Ralstonia solanacearum in eggplant. Theor. Appl. Genet. 126: 143-158.

Lewis, J. D., Wilton, M., Mott, G. A., Lu, W., Hassan, J. A., Guttman, D. S., and Desveaux, D. 2014. Immunomodulation by the Pseudomonas syringae HopZ type III effector family in Arabidopsis. PLoS One 9:e116152.

Li, J., Liu, H., Cao, J., Chen, L., Gu, C., Allen, C., and Guo, J. 2010. PopW of Ralstonia solanacearum, a new two-domain harpin targeting the plant cell wall. Mol. Plant Pathol. 11:371-381.

Lin, Y., Chou, I., Wang, J., Ho, F., Chu, Y., Huang, P., Lu, D., Shen, H., Elbaz, M., Huang, S., and Cheng, C. 2008. Transposon mutagenesis reveals differential pathogenesis of Ralstonia solanacearum on tomato and Arabidopsis. Mol. Plant-Microbe Interact. 21:1261-1270.

Lin, Y. H., Huang, H. E., Wu, F. S., Ger, M. J., Liao, P. L., Chen, Y. R., Tzeng, K. C., and Feng, T. Y. 2010. Plant ferredoxin-like protein (PFLP) outside chloroplast in Arabidopsis enhances disease resistance against bacterial pathogens. Plant Sci. 179:450-458.

Liu, Y., Kanda, A., Kiba, A., Hikichi, Y., and Ohnishi, K. 2009. Distribution of avirulence genes avrA and popP1 in 22 Japanese phylotype I strains of Ralstonia solanacearum. J. Gen. Plant Pathol. 75:362-368.

Macho, A. P., Guidot, A., Barberis, P., Beuzcon, C. R., and Genin, S. 2010. A competitive index assay identifies several Ralstonia solanacearum Type III effector mutant strains with reduced fitness in host plants. Mol. PlantMicrobe Interact. 23:1197-1205.

Maechler, M., Rousseeuw, P., Struyf, A., Hubert, M., and Hornik, K. 2015. Cluster: Cluster Analysis Basics and Extensions. R package version 2.0.1. https://cran.r-project.org/web/packages/cluster/index

McDonald, B. A., and Linde, C. 2002. Pathogen population genetics, evolutionary potential, and durable resistance. Annu. Rev. Phytopathol. 40:349-379.

N'Guessan, C. A., Abo, K., Fondio, L., Chiroleu, F., Lebeau, A., Poussier, S., Wicker, E., and Kone, D. 2012. So near and yet so far: The specific case of Ralstonia solanacearum populations from Cote d'Ivoire in Africa. Phytopathology 102:733-740.

Nahar, K., Matsumoto, I., Taguchi, F., Inagaki, Y., Yamamoto, M., Toyoda, K., Shiraishi, T., Ichinose, Y., and Mukaihara, T. 2014. Ralstonia solanacearum type III secretion system effector Rip36 induces a hypersensitive response in the nonhost wild eggplant Solanum torvum. Mol. Plant Pathol. 15: 297-303.

Palloix, A., Aymé, V., and Moury, B. 2009. Durability of plant major resistance genes to pathogens depends on the genetic background, experimental evidence and consequences for breeding strategies. New Phytol. 183:190-199.
Peeters, N., Carrere, S., Anisimova, M., Plener, L., Cazale, A. C., and Genin, S. 2013. Repertoire, unified nomenclature and evolution of the Type III effector gene set in the Ralstonia solanacearum species complex. BMC Genomics 14:859.

Poueymiro, M., Cunnac, S., Barberis, P., Deslandes, L., Peeters, N., Cazale-Noel, A. C., Boucher, C., and Genin, S. 2009. Two type III secretion system effectors from Ralstonia solanacearum GMI1000 determine host-range specificity on tobacco. Mol. Plant-Microbe Interact. 22:538-550.

Poueymiro, M., and Genin, S. 2009. Secreted proteins from Ralstonia solanacearum: A hundred tricks to kill a plant. Curr. Opin. Microbiol. 12: 44-52.

Prior, P., Bart, S., Leclercq, S., Darrasse, A., and Anaïs, G. 1996. Resistance to bacterial wilt in tomato as discerned by spread of Pseudomonas (Burkholderia) solanacearum in the stem tissues. Plant Pathol. 45: 720-726.

Quenouille, J., Paulhiac, E., Moury, B., and Palloix, A. 2014. Quantitative trait loci from the host genetic background modulate the durability of a resistance gene: A rational basis for sustainable resistance breeding in plants. Heredity 112:579-587.

R Development Core Team. 2013. R: A Language and Environment for Statistical Computing. R Foundation for Statistical Computing, Vienna, Austria.

Remenant, B., Coupat-Goutaland, B., Guidot, A., Cellier, G., Wicker, E., Allen, C., Fegan, M., Pruvost, O., Elbaz, M., Calteau, A., Salvignol, G., Mornico, D., Mangenot, S., Barbe, V., Medigue, C., and Prior, P. 2010. Genomes of three tomato pathogens within the Ralstonia solanacearum species complex reveal significant evolutionary divergence. BMC Genomics 11:379.

Remigi, P., Anisimova, M., Guidot, A., Genin, S., and Peeters, N. 2011. Functional diversification of the GALA type III effector family contributes to Ralstonia solanacearum adaptation on different plant hosts. New Phytol. 192:976-987.

Sarris, P. F., Duxbury, Z., Huh, S. U., Ma, Y., Segonzac, C., Sklenar, J., Derbyshire, P., Cevik, V., Rallapalli, G., Saucet, S. B., Wirthmueller, L., Menke, F. L., Sohn, K. H., and Jones, J. D. 2015. A plant immune receptor detects pathogen effectors that target WRKY transcription factors. Cell 161: 1089-1100.

Sharlach, M., Dahlbeck, D., Liu, L., Chiu, J., Jimenez-Gomez, J. M., Kimura, S., Koenig, D., Maloof, J. N., Sinha, N., Minsavage, G. V., Jones, J. B., Stall, R. E., and Staskawicz, B. J. 2013. Fine genetic mapping of RXopJ4, a bacterial spot disease resistance locus from Solanum pennellii LA716. Theor. Appl. Genet. 126:601-609.

Sole, M., Popa, C., Mith, O., Sohn, K., Jones, J. D. G., Deslandes, L., and Valls, M. 2012. The awr gene family encodes a novel class of Ralstonia solanacearum type III effectors displaying virulence and avirulence activities. Mol. Plant-Microbe Interact. 25:941-953.

Strange, R. N., and Scott, P. R. 2005. Plant disease: A threat to global food security. Annu. Rev. Phytopathol. 43:83-116.

Tans-Kersten, J., Brown, D., and Allen, C. 2004. Swimming motility, a virulence trait of Ralstonia solanacearum, is regulated by FlhDC and the plant host environment. Mol. Plant-Microbe Interact. 17:686-695.

Tans-Kersten, J., Huang, H. Y., and Allen, C. 2001. Ralstonia solanacearum needs motility for invasive virulence on tomato. J. Bacteriol. 183:3597-3605.

Tasset, C., Bernoux, M., Jauneau, A., Pouzet, C., Briere, C., Kieffer-Jacquinod, S., Rivas, S., Marco, Y., and Deslandes, L. 2010. Autoacetylation of the Ralstonia solanacearum effector PopP2 targets a lysine residue essential for RRS1-R-mediated immunity in Arabidopsis. PLoS Pathog. 6:e1001202.

Truong, H. T. H., Esch, E., and Wang, J. 2008. Resistance to Taiwanese race 1 strains of Ralstonia solanacearum in wild tomato germplasm. Eur. J. Plant Pathol. 122:471-479.

Turner, M., Jauneau, A., Genin, S., Tavella, M. J., Vailleau, F., Gentzbittel, L., and Jardinaud, M. F. 2009. Dissection of bacterial wilt on Medicago truncatula revealed two type III secretion system effectors acting on root infection process and disease development. Plant Physiol. 150: 1713-1722.

Ustun, S., Bartetzko, V., and Bornke, F. 2013. The Xanthomonas campestris type III effector XopJ targets the host cell proteasome to suppress salicylicacid mediated plant defence. PLoS Pathog. 9:e1003427.

Vailleau, F., Sartorel, E., Jardinaud, M. F., Chardon, F., Genin, S., Huguet, T., Gentzbittel, L., and Petitprez, M. A. 2007. Characterization of the interaction between the bacterial wilt pathogen Ralstonia solanacearum and the model legume plant Medicago truncatula. Mol. Plant-Microbe Interact. 20:159-167.

van den Bosch, F., and Gilligan, C. A. 2003. Measures of durability of resistance. Phytopathology 93:616-625.

Venables, W. N., and Ripley, B. D. 2002. Modern Applied Statistics with S. 4th ed. Springer, New York. 
Wang, J., Olivier, J., Thoquet, P., Mangin, B., Sauviac, L., and Grimsley, N. 2000. Resistance of tomato line Hawaii7996 to Ralstonia solanacearum Pss4 in Taiwan is controlled mainly by a major strain-specific locus. Mol. Plant-Microbe Interact. 13:6-13.

Wang, J.-F., Hanson, P., and Barnes, J. A. 1998. World-wide evaluation of an international set of resistant sources to bacterial wilt in tomato. Pages 269-275 in: Bacterial Wilt Disease-Molecular and Ecological Aspects. P. Prior, C. Allen, and J. G. Elphinstone, eds. Springer-Verlag, Berlin.

Wang, J.-F., Ho, F.-I., Truong, H. T. H., Huang, S.-M., Balatero, C. H., Dittapongpitch, V., and Hidayati, N. 2013. Identification of major QTLs associated with stable resistance of tomato cultivar 'Hawaii 7996' to Ralstonia solanacearum. Euphytica 190:241-252.

Wicker, E., Grassart, L., Coranson-Beaudu, R., Mian, D., Guilbaud, C., Fegan, M., and Prior, P. 2007. Ralstonia solanacearum strains from Martinique
(French west indies) exhibiting a new pathogenic potential. Appl. Environ. Microbiol. 73:6790-6801.

Wicker, E., Lefeuvre, P., Cambiaire, J. C. d., Lemaire, C., Poussier, S., and Prior, P. 2012. Contrasting recombination patterns and demographic histories of the plant pathogen Ralstonia solanacearum inferred from MLSA. ISME J. 6:961-974.

Xiao, X. o., Cao, B., Li, G., Lei, J., Chen, Q., Jiang, J., and Cheng, Y. 2014. Functional characterization of a putative bacterial wilt resistance gene $(R E-b w)$ in eggplant. Plant Mol. Biol. Rep. Published online. doi:10.1007/s11105-014-0814-1

Yao, J., and Allen, C. 2006. Chemotaxis is required for virulence and competitive fitness of the bacterial wilt pathogen Ralstonia solanacearum. J. Bacteriol. 188:3697-3708.

Yao, J., and Allen, C. 2007. The plant pathogen Ralstonia solanacearum needs aerotaxis for normal biofilm formation and interactions with its tomato host. J. Bacteriol. 189:6415-6424. 